\title{
The Redistributive Role of Unemployment Benefits*
}

\author{
Lawrence Uren ${ }^{\dagger}$
}

February 23, 2018

\begin{abstract}
This paper evaluates the role of unemployment benefits as a tool for redistribution. In a setting with worker heterogeneity, the provision of unemployment benefits achieves two goals: it provides insurance to workers in the event of job loss and it redistributes wealth from individuals with more to those with fewer economic opportunities. Our model features a frictional labour market and an incomplete financial market. When calibrated to match stylised facts of the US economy, the optimal level of unemployment benefits is broadly similar regardless of whether workers differ in economic opportunities. This suggests that taking into consideration the redistributive nature of unemployment benefits has only a limited role in altering the optimal level of unemployment benefits.
\end{abstract}

Keywords: incomplete markets, frictional labour markets, unemployment insurance, inequality

*The author would like to thank Satyajit Chatterjee, Mei Dong, Chris Edmond, Per Krusell, Vincenzo Quadrini, Thijs van Rens, Ayşegül Şahin, Ludo Visschers, Jacob Wong and seminar participants at the University of Adelaide, Monash University, the University of Queensland, the University of Sydney, the Konstanz-Essex Labour Market Search Workshop and the University of Pompeu Fabra Macro-Labour Workshop for useful comments and discussion. All remaining errors are my own. This is a substantially modified version of a previous working paper entitled "Equilibrium Unemployment with Incomplete Markets".

$\dagger$ Department of Economics, University of Melbourne, Parkville, Victoria 3010, Australia. luren@unimelb.edu.au 


\section{Introduction}

The primary rationale for a system of unemployment benefits is that it insures workers against unexpected job loss. This helps individuals to smooth consumption over time when facing employment shocks in the presence of credit constraints. A second rationale for the existence of unemployment benefits is that it can act as a means of redistributing wealth from the rich to the poor. The basic theory, as expounded in Marceau and Boadway (1994), suggests that workers differ in their skills and this leads to signficant differences in economic outcomes. If a social planner cares about an equitable distribution of welfare, unemployment benefits may be used to reduce dispersion in consumption. For such a policy to be successful, it is necessary that more skilled workers have greater economic opportunities as reflected in higher wages and lower unemployment rates. Certainly when comparing labour market outcomes of different educational groups these conditions are satisfied.

This paper investigates how this motive for redistribution across skill types alters the optimal level of unemployment benefits. To do so, we develop a model with frictional labour markets in which heterogeneous workers face employment risk but mitigate this risk by participating in an incomplete financial market. In our model workers and firms form job matches in a frictional labour market. We adopt the directed search approach introduced by Moen (1997) and Acemoglu and Shimer (1999) in which firms create vacancies with a posted wage to attract workers. In financial markets, workers mitigate risk by trading annuities and firms borrow to fund an initial capital investment. In the goods market, workers make optimal consumption decisions and firms make optimal investment decisions. In equilibrium, the total consumption and investment equals the amount of output produced by worker-firm matches. Imposing equilibrium in these markets allows us to pin down a steady state interest rate, level of output, and unemployment rate.

In our environment the introduction of unemployment benefits affects welfare through a number of mechanisms. First, in the absence of complete markets unemployment benefits provide a form of insurance for workers subject to employment risk. Second, the introduction of unemployment benefits is financed via the taxation of employed workers which acts to reduce match surplus. Hence the introduction of unemployment benefits reduces the incentive to create vacancies and raises the unemployment rate. Third, the provision of unemployment benefits alters the equilibrium search behaviour of workers and firms in a setting with directed search. As highlighted by Acemoglu and Shimer (1999), the provision of public insurance encourages workers to spend more time searching and firms respond by creating more productive (higher capital) jobs.

Finally, changes in unemployment benefits alter the equilibrium interest rate since unemployment benefits affect both consumption-saving decisions of workers and the investment decisions and the output produced by firms. In this model the interest rate adjusts to ensure the goods market is in equilibrium. 
Using this model we revisit the effect of unemployment benefits on welfare. We begin by considering a setting in which workers are homogeneous and calibrate the model to match key features of the US economy. We then consider welfare implications of varying the level of unemployment benefits. To evaluate changes in welfare we calculate the compensating variation associated with a policy change. By aggregating across workers, we can determine whether an economy would require either net positive or negative transfers to compensate individuals following a policy change. In our setting with homogeneous workers we find that the optimal replacement rate (the ratio of unemployment benefits to average wages) is only around 12 per cent which is lower than the replacement rate in the USA.

In reality there is widespread evidence of worker heterogeneity along many dimensions. In our second calibration workers are ex ante heterogeneous. They differ in terms of productivity, job stability and the ability to find jobs. ${ }^{1}$ We form groups based upon educational attainment and calibrate the model to match key features of the US economy including differences in labour market outcomes across educational groups. We then reconsider the effect of varying the level of unemployment benefits in this setting. Unlike the case with homogeneous workers, unemployment benefits play a redistributive role in transferring wealth across individuals with differences in skill. We find that in this setting the optimal replacement rate is close to zero. That is, adding heterogeneity in a reasonable manner to the model does not increase the optimal level of benefits.

We also examine how the structure of unemployment insurance systems affects equilibrium outcomes. In many countries like the USA, the generosity of unemployment benefits is linked to an individual's previous income. In contrast, in Australia and a number of other countries, unemployment benefits provide a fixed amount independent of previous work experience. ${ }^{2}$ In our model, with an ex ante homogeneous workforce, it is irrelvant to economic outcomes whether workers receive benefits proportional to their previous income or fixed benefits independent of previous income. However, when workers are heterogeneous in ability, different unemployment insurance systems lead to different levels of redistribution and as a result different economic outcomes. We evaluate these different unemployment insurance systems and find that although the overall welfare effect is quite similar, they do have different implications on the unemployment outcomes of different groups.

Our results differ from the previous literature in a number of ways. Costain (1995), Pollak (2007), Krusell, Mukoyama and Şahin (2010) and Mukoyama (2013) examine unemployment insurance in an environment with incomplete markets and random search. They focus upon settings with homogeneous workers and the optimal replacement rate is typically below the current levels observed in the US. As in our model unem-

\footnotetext{
${ }^{1}$ Clearly, workers could differ along other dimensions, such as time discount rates and attitudes towards risk. See Lawrance (1991) for a discussion of time preference heterogeneity.

${ }^{2}$ Some countries, such as Germany, have hybrid systems where some components are fixed and others are proportional to previous income.
} 
ployment benefits provide additional consumption insurance, but also raise wages and discourage vacancy creation. Our study differs from these previous studies for two main reasons. First, as in Acemoglu and Shimer (1999), providing unemployment benefits to risk averse workers in a directed search environment may improve efficiency. Workers are willing to take on more risk in the presence of greater (public) insurance and firms respond by offering fewer but more productive (higher capital) jobs. This mechanism is absent from the above-mentioned papers. Second, in contrast to Acemoglu and Shimer (1999) the real interest rate adjusts to equate supply and demand which has important implications upon the optimal level of unemployment benefits. Lifschitz, Setty and Yedid-Levi (2016) extend Krusell, Mukoyama and Şahin (2010) to also consider worker heterogeneity based upon differences in education. They argue that unemployment insurance has a redistributive role and that optimal replacement rate is significantly higher with ex ante heterogeneity. In their work, the optimal replacement rate more than doubles (from 15 per cent to 33 per cent) when heterogeneity is introduced. In contrast, in our work, we find that the optimal replacement rate does not increase.

We view the model developed in Section 2 as being of some independent interest. It is more tractable than competing models that combine incomplete financial markets with frictional labour markets. This arises due to two key assumptions. First, preferences are described by CARA utility while previous models have typically assumed CRRA preferences. Second, workers and firms match in a directed search environment. The use of CARA utility simplifies the consumption problem so that saving decisions are independent of asset holdings. This result allows us to describe the steady state wealth distribution and calculate the equilibrium level of assets in closed form without resorting to simulation. Second, as Acemoglu and Shimer (1999) highlight, combining directed search with CARA utility implies that wages may vary by inherent worker characteristics but they do not vary by wealth levels. ${ }^{3}$ So if workers are more productive or patient they may receive higher wages but wages do not depend upon wealth. As a result, our steady state equilibrium can be described as the solution to a system of non-linear equations and allows for a complete characterisation of the distribution of wealth, consumption and welfare unlike competing discrete time methods.

There are a number of related papers on consumption decisions with risk averse agents facing uncertainty due to labour market transitions. Examples include Flemming (1978), Lise (2007), Browning, Crossley and Smith (2007), Shimer and Werning (2007) and Shimer and Werning (2008). None of these papers integrates risk averse workers into a general equilibrium model with endogenous output, unemployment and interest rate. A small number of papers examine equilibrium unemployment with incomplete markets using a Lucas-Prescott (1974) approach: Gomes, Greenwood and Rebelo (2001) and Krusell, Mukoyama, Şahin and Rogerson (2008) are examples. ${ }^{4}$

\footnotetext{
${ }^{3}$ In contrast, with Nash Bargaining wages depend not only upon worker characteristics but also on asset holdings since asset levels determine reservation utilities.

${ }^{4}$ Of course, other aspects of unemployment benefits have been explored. See Hansen and Imrohorglu (1992) or Hopenhayn and Nicolini (1997) for a discussion of moral hazard. Geromichalos (2015) studies the method of financing unemployment
} 
Section 2 presents the model and characterises the equilibrium. In Section 3, the model is calibrated. Section 4 and 5 discuss our main application; the effect of unemployment insurance upon welfare with homogeneous and heterogeneous workers. Section 6 investigates the differences in outcomes under different unemployment insurance systems. Section 7 concludes.

\section{The Model}

Time is continuous. The economy is inhabited by a set of workers with mass normalised to one and a large set of firms. These agents interact in a labour, a product and a financial market. Workers die at a Poisson arrival rate of $d$ and are replaced by newly born workers of the same type so that the overall composition and size of the population remains constant. Individuals enter the economy unemployed and with zero assets. In the labour market, workers supply labour to firms in return for a wage. The labour market is frictional with vacancy creation, wages and capital investment decisions determined in a competitive search environment similar to Moen (1997) and Acemoglu and Shimer (1999). In the frictionless product market output serves two purposes: it is consumed by workers and used for investment purposes by firms. The financial market is incomplete. Rather than having access to a complete set of contingent securities, agents trade in annuities that offer a fixed rate of return, as in a Blanchard-Yaari economy. This implies that the wealth of individuals who die is redistributed to agents through an interest rate premium.

In equilibrium, workers make utility maximising consumption-saving decisions, firms maximise profits, and the labour, financial and product markets clear. First, in a partial equilibrium setting we solve for the consumption decision of households given exogenous income and interest rates. Given these consumption decisions, we solve for the steady state wealth distribution. Then we discuss the entry decisions of firms and how equilibrium conditions in each market pin down the interest rate, output, capital per worker, vacancies and unemployment.

\subsection{Households Consumption Decisions and the Wealth Distribution}

A worker is associated with a group $j$ where $j \in\{1,2, \cdots, J\}$. Worker types vary in productivity and potentially other characteristics although workers within a group are ex ante identical. ${ }^{5}$ Let $\pi_{j}$ denote the mass of workers of type $j$ and $\sum_{j=1}^{J} \pi_{j}=1$. Workers maximise the present discounted value of utility from consumption. They have access to a risk-free asset that allows them to lend or borrow at an interest rate of $r$. Their income follows a stochastic process that depends upon their employment state, which we will benefits in a directed search setting.

${ }^{5}$ That is, they have the same innate characteristics but due to luck vary in wealth over time, and as a result make different consumption decisions and receive different utility. 
denote by $i \in\{e, u\}$ to indicate whether a worker is employed or unemployed, respectively.

When a worker of type $j$ is employed, they receive an after-tax income of $y_{e, j}=(1-\tau) w_{j}$ where $w_{j}$ is the wage paid by a firm to a worker of type $j$ and $\tau$ is the income tax rate. When unemployed, we assume they will engage in home production producing $z_{j}$ units of output and receive unemployment benefits, $b w_{j}$, from the government where $b$ is the replacement rate. The net income of an unemployed individual is $y_{u, j}=z_{j}+b w_{j}$. For the moment, assume that an unemployed individual of type $j$ finds a job at an exogenous Poisson arrival rate of $\lambda_{j}$ and loses a job at an exogenous Poisson arrival rate of $\delta_{j} .{ }^{6}$ Finally, workers die at a rate of $d$ and discount future utility at a rate of $\rho$.

Formally, a type $j$ individual worker with employment status $i$ selects consumption, $c_{i, j}(t)$, to solve,

$$
\max _{c_{i, j}(t)} E_{t} \int_{0}^{\infty} e^{-(\rho+d) t} u\left(c_{i, j}(t)\right) d t
$$

subject to the evolution of assets $\dot{a}=r \cdot a+y_{i, j}(t)-c_{i, j}(t)$ which depends upon employment status and a No-Ponzi condition that states $\lim _{t \rightarrow \infty} e^{-r t} a(t)=0$. Following Shimer and Werning (2007) and Shimer and Werning (2008), assume that individuals have CARA preferences. ${ }^{7}$ That is, $u(c)=-e^{-\gamma c}$ where $\gamma$ is a measure of absolute risk aversion.

Proposition 1. Given the consumption problem described above, the value function describing the maximum expected utility that a worker of type $j$ in employment state $i$ with asset holdings, a, is:

$$
V_{i, j}(a)=-\frac{e^{-\gamma\left(r a+b_{i, j}+\frac{\rho+d-r}{\gamma r}\right)}}{r}
$$

and the optimal consumption plan is:

$$
c_{i, j}(a)=r \cdot a+b_{i, j}+\frac{\rho+d-r}{\gamma r}
$$

where $b_{i, j}$ solve the following nonlinear system of equations,

$$
\begin{aligned}
& \lambda_{j} e^{-\gamma b_{e, j}}=\left(\gamma r\left(y_{u, j}-b_{u, j}\right)+\lambda_{j}\right) e^{-\gamma b_{u, j}} \\
& \delta_{j} e^{-\gamma b_{u, j}}=\left(\gamma r\left(y_{e, j}-b_{e, j}\right)+\delta_{j}\right) e^{-\gamma b_{e, j}}
\end{aligned}
$$

$A$ unique solution exists and $b_{e, j}>b_{u, j}$ if $y_{e, j}>y_{u, j}$ and $r>0$.

The details of the proof are in the Appendix, but it follows closely from results contained in Shimer and Werning (2007) and Wang (2007). A convenient (for the purposes of the solving the model) but unrealistic

\footnotetext{
${ }^{6}$ In equilibrium, wages and the job arrival rate will be determined endogenously. We do not attempt to explain the job destruction rate or the value of home production.

${ }^{7}$ CARA utility has the unattractive property that some workers will consume negative amounts in equilibrium. In our numerical simulations this accounts for a tiny portion of the overall population.
} 
feature of CARA utility is that consumption may become negative. In our calibrations the percentage of individuals with negative consumption is exceedingly small. ${ }^{8}$

With CARA utility, workers consume their interest income, an amount that depends upon their employment status denoted $b_{i, j}$, and an amount that depends upon the rate of discounting, $\rho+d$, relative to the market rate of interest, $r$. This consumption plan implies

$$
\dot{a}_{j}=y_{i, j}-b_{i, j}-\frac{\rho+d-r}{\gamma r} .
$$

Thus, conditional upon worker type, asset accumulation is independent of the level of wealth and depends solely upon employment status. This lack of a wealth effect in saving decisions is a direct consequence of the CARA utility specification. Now consider a setting with a large number of ex ante identical workers and assume the stochastic arrival of job finding and job destruction are independent. The independence of consumption-saving decisions from wealth makes it possible to characterise the evolution of the wealth distribution and to solve for the steady state distribution of wealth of type $j$ workers. To do so, define $F_{j}(a, t)$ the mass of employed workers of type $j$ with wealth equal to or less than the level $a$ at time $t$. Similarly, define $G_{j}(a, t)$ the mass of unemployed workers of type $j$ with wealth equal to or less than $a$ at time $t$. The evolution of these distributions satisfy the following system of partial differential equations,

$$
\frac{\partial F_{j}(a, t)}{\partial t}=\lambda_{j} \cdot G_{j}(a, t)-\left(\delta_{j}+d\right) \cdot F_{j}(a, t)-\left(y_{e, j}-b_{e, j}-\frac{\rho+d-r}{\gamma r}\right) \cdot \frac{\partial F_{j}(a, t)}{\partial a}
$$

and

$$
\frac{\partial G_{j}(a, t)}{\partial t}=\delta_{j} \cdot F_{j}(a, t)-\left(\lambda_{j}+d\right) \cdot G_{j}(a, t)-\left(y_{u, j}-b_{u, j}-\frac{\rho+d-r}{\gamma r}\right) \cdot \frac{\partial G_{j}(a, t)}{\partial a}+d
$$

if $a>0$ and

$$
\frac{\partial G_{j}(a, t)}{\partial t}=\delta_{j} \cdot F_{j}(a, t)-\left(\lambda_{j}+d\right) \cdot G_{j}(a, t)-\left(y_{u, j}-b_{u, j}-\frac{\rho+d-r}{\gamma r}\right) \cdot \frac{\partial G_{j}(a, t)}{\partial a}
$$

if $a<0$.

The interpretation of these equations is relatively straightforward. ${ }^{9}$ Consider the first equation. The number of employed workers with assets below $a$ varies since some unemployed workers find jobs, some employed workers lose jobs, and some employed workers save enough to move from below $a$ to above $a$. Looking at these in turn, a mass of $G_{j}(a, t)$ unemployed workers with assets below $a$ become employed workers at a rate of $\lambda_{j}$. A mass of $F_{j}(a, t)$ employed workers with assets less than $a$ will lose jobs or exit the economy at a rate of $\left(\delta_{j}+d\right)$. Finally, a set of $\frac{\partial F_{j}(a, t)}{\partial a}$ employed workers with wealth close to $a$ will exit from $F_{j}(a, t)$ due to their savings. The discontinuity in behaviour at $a=0$ in characterising $G_{j}(a, t)$ arises because individuals exiting the economy are replaced by unemployed individuals with zero assets.

\footnotetext{
${ }^{8}$ In our baseline homogeneous worker calibration the proportion of workers with negative consumption is approximately $5 \times 10^{-18}$. In our baseline heterogeneous calibration the proportion of workers with negative consumption is of similar magnitude. ${ }^{9}$ See Diamond and Yellin (1985) and Diamond and Yellin (1990) for different but related applications.
} 
Our analysis focuses up a steady state in which the distribution of assets is constant over time so that $\frac{\partial G_{j}(a, t)}{\partial t}=\frac{\partial F_{j}(a, t)}{\partial t}=0$. Dropping time subscripts we define $F_{j}(a)$ and $G_{j}(a)$ as the corresponding steady state distributions. The equilibrium steady state distributions, $F_{j}(a)$ and $G_{j}(a)$, can be described as a solution to a system of linear differential equations. In matrix form,

$$
\left(\begin{array}{c}
\left(y_{e, j}-b_{e, j}-\frac{\rho+d-r}{\gamma r}\right) \cdot F_{j}^{\prime}(a) \\
\left(y_{u, j}-b_{u, j}-\frac{\rho+d-r}{\gamma r}\right) \cdot G_{j}^{\prime}(a)
\end{array}\right)=\left(\begin{array}{cc}
-\left(\delta_{j}+d\right) & \lambda_{j} \\
\delta_{j} & -\left(\lambda_{j}+d\right)
\end{array}\right)\left(\begin{array}{c}
F_{j}(a) \\
G_{j}(a)
\end{array}\right)
$$

if $a<0$ and

$$
\left(\begin{array}{c}
\left(y_{e, j}-b_{e, j}-\frac{\rho+d-r}{\gamma r}\right) \cdot F_{j}^{\prime}(a) \\
\left(y_{u, j}-b_{u, j}-\frac{\rho+d-r}{\gamma r}\right) \cdot G_{j}^{\prime}(a)
\end{array}\right)=\left(\begin{array}{cc}
-\left(\delta_{j}+d\right) & \lambda_{j} \\
\delta_{j} & -\left(\lambda_{j}+d\right)
\end{array}\right)\left(\begin{array}{c}
F_{j}(a) \\
G_{j}(a)
\end{array}\right)+\left(\begin{array}{c}
0 \\
d
\end{array}\right)
$$

if $a>0$. We can combine the above system of differential equations with boundary conditions imposed by the economic nature of the problem to solve for the explicit distribution of assets. These boundary conditions are $\lim _{a \rightarrow-\infty} F_{j}(a)=\lim _{a \rightarrow-\infty} G_{j}(a)=0$ and $\lim _{a \rightarrow \infty} F_{j}(a)=\left(\pi_{j}-u_{j}\right)$ and $\lim _{a \rightarrow \infty} G(a)=u_{j}$ where $u_{j}$ is the level of unemployment of type $j$. This leads to our next Proposition.

Proposition 2. Consider the case with precautionary savings in which $y_{e, j}-b_{e, j}-\frac{\rho+d-r}{\gamma r}>0$ and $y_{u, j}-$ $b_{u, j}-\frac{\rho+d-r}{\gamma r}<0$. In steady state the mass of employed workers with wealth less than a and the mass of unemployed workers with wealth less than a are described by $F_{j}(a)$ and $G_{j}(a)$, respectively. Explicitly:

$$
\begin{gathered}
F_{j}(a)= \begin{cases}\pi_{j} C_{1} \xi_{11} e^{\phi_{1} a} & \text { if } a<0 \\
\pi_{j}\left(C_{2} \xi_{21} e^{\phi_{2} a}+C_{F}\right) & \text { if } a>0\end{cases} \\
G(a)= \begin{cases}\pi_{j} C_{1} e^{\phi_{1} a} & \text { if } a<0 \\
\pi_{j}\left(C_{2} e^{\phi_{2} a}+C_{G}\right) & \text { if } a>0\end{cases}
\end{gathered}
$$

where $\phi_{1}>0$ and $\phi_{2}<0$ are eigenvalues associated with the characteristic equation and

$$
\begin{aligned}
C_{2} & =\frac{\phi_{1}\left(\delta+d_{j}+\left(y_{e, j}-b_{e, j}-\frac{\rho+d-r}{\gamma r}\right) \phi_{2}\right)}{\left(\delta_{j}+d+\lambda_{j}\right)\left(\phi_{2}-\phi_{1}\right)} \\
C_{1} & =C_{2}+\frac{\delta_{j}+d}{\delta_{j}+d+\lambda_{j}} \\
\xi_{11} & =\frac{\lambda_{j}}{\delta_{j}+d+\left(y_{e, j}-b_{e, j}-\frac{\rho+d-r}{\gamma r}\right) \phi_{1}} \\
\xi_{21} & =\frac{\lambda_{j}}{\delta_{j}+d+\left(y_{e, j}-b_{e, j}-\frac{\rho+d-r}{\gamma r}\right) \phi_{2}} \\
C_{F} & =\frac{\lambda_{j}}{\lambda_{j}+\delta_{j}+d} \\
C_{G} & =\frac{\delta_{j}+d}{\lambda_{j}+\delta_{j}+d}
\end{aligned}
$$

The aggregate level of assets owned by workers of group $j$ :

$$
A_{j}=\frac{1}{d}\left(\left(\pi_{j}-u_{j}\right)\left(y_{e, j}-b_{e, j}\right)+u_{j}\left(y_{u, j}-b_{u, j}\right)+\pi_{j}\left(\frac{r-\rho-d}{\gamma r}\right)\right)
$$


where the steady state unemployment level of group $j$

$$
u_{j}=\frac{\pi_{j}\left(\delta_{j}+d\right)}{\delta_{j}+d+\lambda_{j}}
$$

The proof is in the Appendix. There is a natural interpretation of equation (4) that describes the aggregate asset holdings. With a Poisson rate of death, the average life expectancy is $1 / d$ periods. Aggregating over workers, the expected proportion of time spent in employment is $\pi_{j}-u_{j}$ during which time a worker saves $y_{e, j}-b_{e, j}-\frac{\rho+d-r}{\gamma r}$ and $u_{j}$ proportion of time spent unemployed during which a worker (dis)saves $y_{u, j}-b_{u, j}-\frac{\rho+d-r}{\gamma r}$. It becomes apparent why a positive rate of death is required for a steady state equilibrium to exist. If agents were infinitely lived, their assets would, in expectation, permanently drift upwards since with CARA utility there is no target level of wealth. Finally, aggregate economy-wide assets are defined as $A=\sum_{j} A_{j}$.

\subsection{Firms, Matching, and the Labour Market}

We endogenise wages, vacancies and capital by using a directed search environment similar to Moen (1997) and Acemoglu and Shimer (1999). Firms create vacancies to attract workers in a frictional labour market. A vacancy specifies the type of worker, $j$, eligible for the vacancy, an amount of capital $k_{j}$, and a posted wage of $w_{j}$. The output produced by a match between a type $j$ worker and firm with $k_{j}$ units of capital is $x_{j} \cdot f\left(k_{j}\right)$ where $x_{j}$ represents productivity that depends upon a worker's type and $f^{\prime}\left(k_{j}\right)>0$ and $f^{\prime \prime}\left(k_{j}\right)<0$. Firms that offer the same $\left(k_{j}, w_{j}\right)$ combination compete in a submarket for type $j$ workers searching for $\left(k_{j}, w_{j}\right)$ jobs. In each submarket frictions exist and are represented by a matching function, $m_{j}\left(u_{j}, v_{j}\right)$, that features constant returns to scale and is increasing in the level of vacancies, $v_{j}$, and unemployment, $u_{j}$. Due to constant returns to scale, the vacancy-unemployment rate in each submarket, $\theta_{j}$, will determine the rate at which workers find jobs, $\lambda_{j}\left(\theta_{j}\right)$ and the rate at which firms find workers, $q_{j}\left(\theta_{j}\right) .{ }^{10}$

The value of a firm with a capital stock $k_{j}$ that has hired a worker of type $j$ at wage $w_{j}$ is denoted $H_{j}\left(k_{j}, w_{j}\right)$. Using standard arguments we can express the steady state value as

$$
r_{f} H_{j}\left(k_{j}, w_{j}\right)=x_{j} f\left(k_{j}\right)-w_{j}+\left(\delta_{j}+d\right)\left(-H_{j}\left(k_{j}, w_{j}\right)\right)
$$

where $r_{f}$ is the rate that a firm discounts future profits and the job match is destroyed if a worker dies or if exogenous destruction occurs. The value of a vacancy with capital $k_{j}$ and posted wage $w_{j}$ is, $N\left(k_{j}, w_{j}\right)$. Explicitly,

$$
r_{f} N\left(k_{j}, w_{j}\right)=q_{j}\left(\theta_{j}\right)\left(H_{j}\left(k_{j}, w_{j}\right)-N\left(k_{j}, w_{j}\right)\right)
$$

\footnotetext{
${ }^{10} \mathrm{As}$ is well known, the rate at which a firm finds a worker is $\frac{m_{j}(u, v)}{v}=m_{j}\left(\frac{u}{v}, 1\right)=m_{j}\left(\frac{1}{\theta}, 1\right)=q_{j}(\theta)$ and the rate at which a worker finds a firm is $\frac{m_{j}(u, v)}{u}=m_{j}\left(1, \frac{v}{u}\right)=m_{j}(1, \theta)=\lambda_{j}(\theta)$.
} 
In an equilibrium with free entry, the benefit of vacancy creation must equal the cost. In this case, the cost equals the amount of capital that a firm purchases so $N\left(k_{j}, w_{j}\right)=k_{j}$.

Following Moen (1997) and Acemoglu and Shimer (1999), vacancy posting decisions solve:

$$
\max _{\left\{k_{j}, w_{j}, \theta_{j}\right\}} V_{u, j}(a)
$$

subject to the zero profit condition $q_{j}\left(\theta_{j}\right)\left(H_{j}\left(k_{j}, w_{j}\right)-k_{j}\right)=r_{f} k_{j}$. In a competitive search environment firms create vacancies, purchase capital and offer wages to maximise the expected value of an unemployed worker subject to the zero profit condition.

The first order conditions associated with this problem imply that $\left(k_{j}, w_{j}, \theta_{j}\right)$ must satisfy the following necessary conditions for optimality: ${ }^{11}$

$$
\begin{aligned}
q_{j}\left(\theta_{j}\right) x_{j} f^{\prime}\left(k_{j}\right)-\left(q_{j}\left(\theta_{j}\right)+r_{f}\right)\left(r_{f}+\delta_{j}+d\right) & =0 \\
\frac{\left(e ^ { \gamma ( b _ { e , j } - b _ { u , j } ) - 1 ) } \left(\delta+r+\gamma r\left((1-\tau) w_{j}-b_{e, j}\right)\right.\right.}{\gamma r(1-\tau)} & =\frac{m_{u} \cdot u_{j}}{m_{v} \cdot v_{j}}\left(x_{j} f\left(k_{j}\right)-w_{j}\right) \cdot\left(\frac{r_{f}}{r_{f}+q_{j}\left(\theta_{j}\right)}\right) \\
\left(\frac{q_{j}\left(\theta_{j}\right)}{q_{j}\left(\theta_{j}\right)+r_{f}}\right)\left(\frac{x_{j} f\left(k_{j}\right)-w_{j}}{r_{f}+\delta_{j}+d}\right) & =k_{j}
\end{aligned}
$$

These conditions are independent of asset holdings so if workers are identical in all respects except for wealth, only a single submarket will be offered in equilibrium. More generally, if there are $J$ worker types then there will only be $J$ submarkets even though there is wealth heterogeneity within worker type. This is a direct consequence of CARA utility. Equation (5) is the frictional analog of the interest rate being equal to the marginal product of capital and it implies that the interest rate, $r$, is related to both the capital stock, $k$, and the ability of firms to find workers, $q(\theta)$. As frictions disappear $(q(\theta) \rightarrow \infty)$, equation (5) becomes $x_{j} f^{\prime}\left(k_{j}\right)=r_{f}+\delta_{j}+d$. Firms may offer jobs at a higher vacancy-unemployment rate, but to continue to satisfy the zero profit condition must offer lower wages. On the other hand, workers are willing to receive lower wages in return for a higher vacancy-unemployment rate which offers them a greater probability of finding employment. Equation (6) states that the marginal rate of substitution between $w$ and $\theta$ in worker's preferences has to equal the marginal rate of transformation between $w$ and $\theta$ by firms satisfying a zero profit condition. Equation (7) is the zero profit condition.

Within a submarket for type $j$ workers the unemployment rate will evolve as follows,

$$
u_{j}=\left(\delta_{j}+d\right)\left(\pi_{j}-u_{j}\right)-\lambda_{j}\left(\theta_{j}\right) u_{j}
$$

\footnotetext{
${ }^{11}$ We assume that when setting wages, firms take into account the effect of wage upon the utility of a worker as a result of receiving higher wage payments when finding employment. However, we assume that wage setting behaviour does not take into account that an increase in wages offered leads to an increase in unemployment benefits. We view this as analogous to the common assumption used in search models that the wage bargained within a match has no effect upon the value of unemployment. See subsection 8.4 for a derivation of these conditions.
} 
and the steady state unemployment level for group $j$ is

$$
u_{j}=\frac{\pi_{j}\left(\delta_{j}+d\right)}{\delta_{j}+d+\lambda_{j}\left(\theta_{j}\right)} .
$$

\subsection{Unemployment Benefits and Taxation}

The magnitude of the unemployment benefit is $b w_{j}$, for each unemployed worker. The benefit is financed by imposing a tax rate, $\tau$, on the income of employed workers. In equilibrium a balanced budget requires,

$$
\sum_{j} u_{j} b w_{j}=\sum_{j} \tau\left(\pi_{j}-u_{j}\right) w_{j}
$$

\subsection{Product and Financial Markets}

In the financial market workers trade an annuity as in a Blanchard-Yaari economy. ${ }^{12}$ Workers may buy or sell an actuarially fair annuity that returns the market return on capital plus a premium related to the rate of death. The relationship between the interest rate that firms face and rate of return on assets by workers is,

$$
r=r_{f}+d
$$

where, $r$ is the return on an annuity, $r_{f}$ is the interest rate that firms face and $d$ is the rate at which workers die. The presence of stochastic death allows financial intermediaries to borrow from consumers at an interest rate $r$, lend to firms at a lower interest rate $r_{f}$. If the value of assets held by workers in the economy is $A$, then firm interest payments are $r_{f} A$. A proportion $d$ of agents die and their assets, $d A$ are distributed to the surviving agents in the economy.

We assume that the product market is frictionless and that the output produced by firms is either consumed by workers or invested by firms. ${ }^{13}$ Denote the quantity of goods supplied by firms and household production as $Y$. Explicitly,

$$
Y=\sum_{j} u_{j} \cdot z+\left(\pi_{j}-u_{j}\right) \cdot x_{j} f\left(k_{j}\right)
$$

Here, supply is simply the sum of output produced by unemployed workers and productive job matches.

\footnotetext{
${ }^{12}$ See Yaari (1965) or Blanchard (1985) for details.

${ }^{13}$ Although we view the introduction of imperfect competition in product markets as interesting and potentially important, we view the competitive product market as a natural baseline case.
} 
Denote $D$ the level of goods demanded by firms and households. Explicitly,

$$
\begin{aligned}
D & =\sum_{j} \pi_{j}\left(\int_{-\infty}^{\infty} c_{u, j}(a) g_{j}(a) d a+\int_{-\infty}^{\infty} c_{e, j}(a) f_{j}(a) d a\right)+k_{j} \cdot \lambda_{j}\left(\theta_{j}\right) \cdot u_{j} \\
& =\sum_{j} u_{j} \cdot b_{u, j}+\left(\pi_{j}-u_{j}\right) \cdot b_{e, j}+\pi_{j} \cdot \frac{\rho+d-r}{\gamma r} \\
& +\frac{r}{d}\left(\left(\pi_{j}-u_{j}\right)\left(y_{e, j}-b_{e, j}\right)+u_{j}\left(y_{u, j}-b_{u, j}\right)+\pi_{j} \frac{r-\rho-d}{\gamma r}\right)+k_{j} \cdot \lambda_{j}\left(\theta_{j}\right) \cdot u_{j} .
\end{aligned}
$$

Demand is the sum of aggregate consumption by households and investment by firms which equals the capital per firm multiplied by the rate at which new firms are created. Product market equilibrium occurs when $Y=D$. The equilibrium interest rate adjusts so that savings will equal investment. In the Appendix, we show how the goods market equilibrium condition can be simplified to:

$$
\sum_{j}\left(\pi_{j}-u_{j}\right)\left(x_{j} f\left(k_{j}\right)-w_{j}\right)=r_{f} A+\sum_{j} k_{j} \lambda_{j} u_{j}
$$

In steady state the profit to firms must equal the interest payment made to owners of assets plus cover the cost of creating new vacancies. This goods market equilibrium condition in conjunction with our free entry condition can be combined to imply:

$$
A=\sum_{j}\left(k_{j} \cdot v_{j}+\left(\pi_{j}-u_{j}\right)\left(\frac{x_{j} f\left(k_{j}\right)-w_{j}}{r_{f}+\delta_{j}+d}\right)\right)
$$

so that the aggregate value of assets in the economy equals the value associated with firms that are matched plus the value of capital stock in current vacancies.

\subsection{Equilibrium}

The above discussion describes a solution to an individual consumption problem with exogenous job transition and interest rates. It also discusses the decisions made by firms for a given interest rate. For each interest rate, $r_{f}$, there is a given level of market tightness that satisfies a free entry condition for firms. This level of market tightness and interest rate, in turn, determines job transition rates and consumption decisions. In contrast to the Acemoglu and Shimer (1999), the interest rate is endogenised by imposing that the product market is in equilibrium with supply equal demand or equivalently, due to Walras' Law, that the financial market is in equilibrium.

For an exogenous tax rate $\tau$, an equilibrium is a vector describing consumption decisions by workers, the level of vacancies created by firms, the level of unemployment, the equilibrium level of wealth, the replacement rate and interest rates such that the following conditions are satisfied:

- Workers make optimal consumption decisions given the stochastic income process they face; 
- Firms make optimal vacancy creation, wage posting and capital purchasing decisions;

- Firms earn zero profits;

- Equilibrium unemployment is consistent with steady state;

- The level of output produced equals consumption by households plus investment by firms;

- The financial market clears with individuals able to trade actuarially fair annuities;

- The equilibrium wealth distribution is consistent with a steady state;

- The unemployment benefit system is self-financed.

Formally for any tax rate, $\tau$, an equilibrium determines $\left(c_{e, j}(a), c_{u, j}(a), k_{j}, v_{j}, u_{j}, w_{j}, A_{j}, r, r_{f}, b\right)$ such that equations (1)-(11) are satisfied. Note that the complete distribution of wealth $\left(F_{j}(a)\right.$ and $\left.G_{j}(a)\right)$ is also determined, but to solve for an equilibrium we only need the aggregate asset holdings. In this setting a steady state equilibrium is a solution to a system of non-linear equations. This differs from Krusell, Muyokama and Şahin (2010) and other incomplete market models where an iterative process must be used to solve for equilibrium. ${ }^{14}$ In our numerical results below, we also consider the case in which $r$ is exogenous and equations (1)-(10) are satisfied. With $r$ exogenous, supply does not equal demand. This would be equivalent to a small open economy in which changes in investment or consumption behaviour do affect equilibrium real interest rates.

The model also has rich implications upon the distribution of other endogenous variables. The distribution of wealth is characterised in Proposition 2. Other key variables such as consumption and expected utility that agents receive are functions of wealth and we can use standard transformations to describe the implied distributions. For completeness, a description of consumption and wealth distributions are provided in the Appendix.

\section{Calibration}

We consider two calibrations of the model to the US economy. Our baseline calibration considers a setting in which workers are ex ante homogeneous. They have identical characteristics but experience different outcomes due to different employment shocks. Our second calibration introduces ex ante worker heterogeneity. In this case, workers are divided into groups on the basis of their educational attainment and vary

\footnotetext{
${ }^{14}$ In a standard incomplete market model, an initial guess for capital stock is made which determines interest rates. Then a dynamic consumption-saving decision is solved, after which the steady state level of capital stock can be determined via simulation. This simulated level of capital stock is used to update the initial guess. Iterate until convergence occurs. The Krusell, Muyokama and Şahin (2010) framework is even more complicated since they use Nash Bargaining which means that wages vary depending upon asset holdings.
} 
Table 1: Parameter Values: Homogeneous Model

\begin{tabular}{clc}
\hline \hline Parameter & Interpretation & Value \\
\hline$\gamma$ & CARA & 5.1 \\
$\rho$ & Discount rate & 0.001 \\
$\mu$ & Matching efficiency & 1.58 \\
$\delta$ & Rate of job destruction & 0.1 \\
$d$ & Rate of death & 0.02 \\
$\alpha$ & Elasticity of matching with respect to $u$ & 0.7 \\
$\phi$ & Capital share of output & 0.4 \\
$x_{1}$ & Productivity & 1 \\
\hline
\end{tabular}

in productivity and other attributes. In both calibrations the model parameters are selected to match a combination of long-run ratios and evidence from microeconomic data. For both calibrations we focus on an annual frequency. ${ }^{15}$ We begin by describing our calibration with homogeneous workers.

Farber (2008) finds that the length of tenure among 40-year old workers is approximately 10 years. Hence, we set the annual rate of job destruction to 0.1. This is significantly lower than the job destruction rate used by Shimer (2005) who calculates a quarterly separation rate of 0.1 or that jobs have an expected length of 2.5 years. The difference reflects that Shimer's measure of the job separation rate is calculated by directly measuring transitions in the CPS. Shimer then assumes that workers face an identical rate of job separation and this rate is independent of employment duration. Krueger, Cramer and Cho (2014) highlight that both of these assumptions are invalid. There is a large amount of duration dependence in labour market transitions and Shimer's value of a quarterly separation rate of 0.1 arises since a small number of workers experience a relatively large number of short job durations.

Individuals die at an annual rate of 0.02 which implies an average life expectancy of 50 years which seems reasonable if we think of workers entering the economy in their early 20s. We assume a Cobb-Douglas matching function; the number of matches formed per unit of time is $m(u, v)=\mu_{j} u_{j}^{\alpha} v_{j}^{1-\alpha}$. We let matching efficiency $\mu_{j}$ vary by worker group but retain a constant $\alpha$ for all groups. There are a wide range of plausible estimates for $\alpha$. For example, using detrended data Shimer (2005) estimates $\alpha=0.72$. In contrast, Borowczyk-Martins, Jolivet and Postel-Vinay (2013) find a value close to 0.3. We settle on a value of $\alpha=0.7$ but our main results are robust to changes in this parameter. For the production function, we assume that a worker-firm match with $k$ units of capital produces $y=x k^{\phi}$. With this production function and wage-setting mechanism the capital share equals $\phi$ which we correspondingly set to $0.4 .{ }^{16}$ We normalise the value of $x=1$ and set $z=0$ to be comparable to Krusell, Mukoyama and Şahin. (2010).

This leaves three parameters to be determined: the degree of risk aversion, $\gamma$, the rate of discounting, $\rho$,

\footnotetext{
${ }^{15}$ Note that the time length of a calibration in a continuous time is a normalization. A quarterly frequency in which the parameters describing rates are divided by four would give identical outcomes.

${ }^{16}$ In equilibrium, with the specified matching and production function the wage workers are paid equals $(1-\phi) x k^{\phi}$ so the labour share is $1-\phi$.
} 
Table 2: Targets: Data and Homogeneous Model

\begin{tabular}{lcc}
\hline \hline Target & Data & Model \\
\hline investment-gdp ratio & 0.20 & 0.30 \\
wealth-income ratio & 10.6 & 5.0 \\
unemployment rate (per cent) & 4.8 & 4.9 \\
real interest rate (per cent) & 5.0 & 5.0 \\
consumption drop upon job loss (per cent) & 6.0 & 2.5 \\
\hline
\end{tabular}

and the degree of matching efficiency, $\mu$. These parameters are selected to minimize the absolute percentage deviation of the endogenous variables from a set of targets described below. ${ }^{17}$ We target an investment to gdp ratio of 0.2 , a wealth to labour income ratio of 10.6 which is the value implied by the 2010 Survey of Consumer Finances and BLS data, an unemployment rate of 4.8 per cent consistent with the average unemployment rate over the period from January 1995 to June 2015, and a real interest rate of firms of 5 per cent. Finally, Aguiar and Hurst (2005) document a 4-8 per cent decline in food consumption upon becoming unemployed. As a result, we target a 6 per cent drop in consumption when a worker with zero assets loses their job. This implies: $\gamma=5.1, \rho=0.001, \mu=1.58$.

Table 1 summarises the parameters for our baseline calibration. The relationship between empirical targets and calibrated model is presented in Table 2. Relative to the observed data, our model generates an excessively high investment-gdp ratio and the model does not capture the wealth-income ratio (10.6 in the data versus 5.0 in our model). Upon losing a job, the consumption of a worker with zero assets declines by 2.5 per cent which is less than the value implied by Aguiar and Hurst (2005), perhaps reflecting that workers are able to self-insure themselves in the model by a greater amount than in reality. Along other dimensions, the model performs well: it closely matches the unemployment rate and the real interest rate.

Our second calibration features ex ante heterogeneous workers with heterogeneity based upon educational attainment. Type I workers are calibrated to match the characteristics of workers who have completed a college degree or higher. Type II workers are calibrated to match the characteristics of workers without a college degree. We set the proportion of Type I workers in the population to equal 0.4, which roughly matches the proportion of workers with college degrees (or higher) in the 2010 Current Population Survey. We normalise the productivity of Type I workers so that $x_{1}=1$ and we retain the values of $\gamma_{1}=\gamma_{2}=5.1$ and $\rho_{1}=\rho_{2}=0.001$ so that our welfare analysis is comparable to our previous calibration. Type I and Type II workers are characterised by the following set of parameters: $\left(\mu_{1}, \delta_{1}\right)$ and $\left(\mu_{2}, x_{2}, \delta_{2}\right)$, respectively. That is, workers vary in productivity, as well as having innate differences in job stability and in their ability to find a job.

\footnotetext{
${ }^{17}$ One of the benefits of the tractability of our model, is that it is possible to do a grid search over a fine area. To calibrate the model we search over a parameter space with 70,000 gridpoints in the homogeneous case and 150,000 in the heterogeneous case.
} 
Table 3: Parameter Values: Heterogeneous Model

\begin{tabular}{clc}
\hline \hline Parameter & Interpretation & Value \\
\hline$\gamma$ & CARA & 5.1 \\
$\rho$ & Discount rate & 0.001 \\
$\mu_{1}$ & Match efficiency (skilled) & 2.36 \\
$\mu_{2}$ & Match efficiency (unskilled) & 1.42 \\
$x_{1}$ & Productivity (skilled) & 1 \\
$x_{2}$ & Productivity (unskilled) & 0.82 \\
$\delta_{1}$ & Job separation rate (skilled) & 0.08 \\
$\delta_{2}$ & Job separation rate (unskilled) & 0.12 \\
$\pi$ & Proportion of high skilled & 0.4 \\
\hline
\end{tabular}

Some of our parameter values are unchanged and constant across worker group: we retain $d=0.02, \alpha=0.7$ and $\phi=0.4$. Cairo and Cajner (2014) document that workers with less education transit more rapidly from employment to unemployment on average. As a result, we allow for type-dependent variation in the job separation rate by setting $\delta_{1}=0.08$ and $\delta_{2}=0.12$.

The remaining parameters $\mu_{1}, \mu_{2}$, and $x_{2}$ are selected to match a set of targets described below. As before, we target an investment-gdp ratio of 0.2 and a real interest rate of 5 per cent for firms. The 2007 Survey of Consumer Finances suggests a wealth-income ratio of 16.4 for high skilled workers and a wealth-income ratio of 6.7 for unskilled workers. Over the period from 1995-2015, the average unemployment rate for unskilled workers and skilled workers is 5.8 and 2.8 , respectively. Finally, workers without college degrees earn only 56 per cent of that earned by workers with a college degree. We target this ratio as the difference between the wages of worker types in our model. The parameters for the model with worker heterogeneity are displayed in Table 3.

The relationship between our data targets and our calibrated model are presented in Table 4. Broadly speaking, the calibration does well in matching several dimensions of the data: it closely matches unemployment rates by skill, the interest rate, and the wage differential between skilled and unskilled workers. The model does less well along other dimensions. In the model, the wealth-income ratio of skilled workers lies below that of unskilled workers while in reality, the converse holds. This arises at least partly due to the fact that in the model, skilled workers face relatively little risk; they find jobs more rapidly and lose jobs less often and hence have less need to self-insure. As in the homogeneous worker case, the model underpredicts the fall in consumption upon job loss and overpredicts the investment-to-GDP ratio. It is perhaps unsurprising that our calibration misses along some dimensions for the following reason: we maintain constant preference parameters across types to make our welfare calculations comparable to the case with homogeneous workers. However, Lawrance (1991) suggests that more educated workers are more patient. If we incorporated variable time discount rates we could reduce some of the discrepancy in wealth-income ratios between the model and the data. 
Table 4: Targets: Data and Heterogeneous Model

\begin{tabular}{lcc}
\hline \hline Target & Data & Model \\
\hline investment-gdp ratio & 0.2 & 0.32 \\
wealth-income ratio, skilled & 16.4 & 4.0 \\
wealth-income ratio, unskilled & 6.7 & 6.8 \\
unemployment rate, skilled (per cent) & 2.8 & 2.8 \\
unemployment rate, unskilled (per cent) & 5.8 & 5.9 \\
real interest rate (per cent) & 5.0 & 4.8 \\
consumption drop upon job loss, skilled & 6.0 & 1.5 \\
consumption drop upon job loss, unskilled & 6.0 & 2.4 \\
wage ratio, unskilled to skilled & 0.56 & 0.59 \\
\hline
\end{tabular}

Table 5: Response to unemployment benefits with homogeneous workers: Aggregate variables

\begin{tabular}{ccccccc}
\hline \hline$\tau$ & benefit rate & $w$ & unemployment & assets & capital/worker & interest rate \\
\hline 0.00 & 0.00 & 1.115 & 4.8 & 5.57 & 4.71 & 0.0504 \\
0.01 & 0.21 & 1.124 & 5.2 & 5.50 & 4.81 & 0.0498 \\
0.02 & 0.36 & 1.133 & 5.5 & 5.43 & 4.90 & 0.0490 \\
0.03 & 0.54 & 1.142 & 5.9 & 5.38 & 5.00 & 0.0483 \\
0.04 & 0.67 & 1.150 & 6.4 & 5.32 & 5.08 & 0.0475 \\
0.05 & 0.77 & 1.157 & 7.0 & 5.27 & 5.17 & 0.0468 \\
0.06 & 0.85 & 1.164 & 7.6 & 5.22 & 5.24 & 0.0460 \\
\hline
\end{tabular}

\section{Unemployment Benefits with Homogeneous Workers}

We now consider the effect of changes in unemployment benefits in our baseline homogeneous worker calibration. Unemployment benefits provide an income of $b w$ to an unemployed worker. They are financed in a revenue neutral manner by imposing a proportional tax of $\tau$ on the income of employed individuals. A range of values of $\tau$ are considered from our baseline of zero to a maximum value of 0.06 . This covers a wide range of generosity in benefit systems; the maximum replacement rate exceeds 70 per cent.

The effect of varying $\tau$ on aggregate outcomes is displayed in Table 5. Some of the responses are similar to those in Krusell, Muyokama and Şahin (2010): the increase in unemployment benefits leads to a rise in unemployment and wages. ${ }^{18}$ Furthermore, the aggregate level of assets in the economy declines since the presence of unemployment benefits reduces the need for self-insurance. There are some important differences. In response to greater unemployment benefits, firms respond by offering better jobs - that is, jobs with higher capital-labour ratios. This result is due to the mechanism highlighted by Acemoglu and Shimer (1999). In the presence of greater unemployment benefits, workers are willing to experience longer unemployment spells in exchange for higher quality jobs. This encourages firms to create vacancies with higher capital per worker.

\footnotetext{
${ }^{18}$ In this calibration, even the magnitude of the wage increase is quite similar to that of Krusell, Muyokama and Şahin (2010). They find moving from a replacement rate of zero to 40 per cent only increases the wage by just over one per cent. See Figure 2 of Krusell, Muyokama and Şahin (2010). In this model, a similar increase in the replacement rate leads to an approximately two per cent increase in wages.
} 


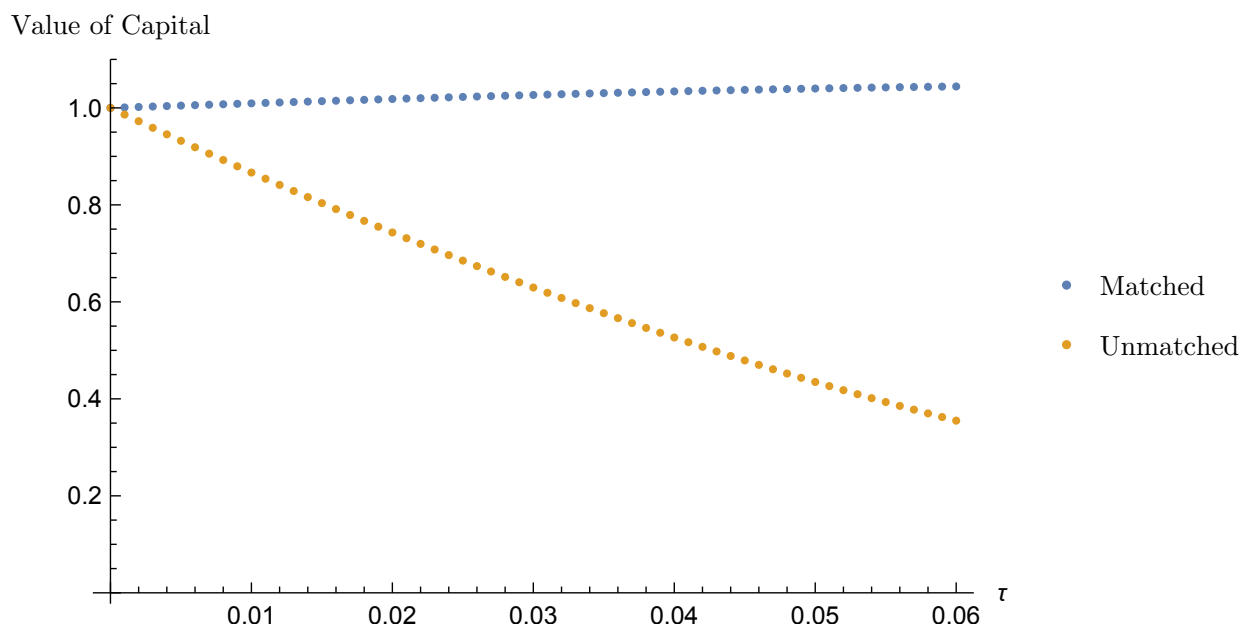

Figure 1: Changes in matched and unmatched capital holdings in response to changes in $\tau$. Values normalised to one in baseline calibration.

We highlight two non-standard effects that are present in this model but absent from competing ones. First, the level of aggregate assets and the capital per worker move in opposite directions in response to changes in unemployment benefits. In incomplete market models with perfect capital markets such as Aiyagari (1994) or Krusell, Mukoyama and Şahin (2010), these variables move together. ${ }^{19}$ Second in response to an increase in unemployment benefits the real interest rate declines. In a standard incomplete market model the public provision of insurance, in this case unemployment benefits, will typically reduce capital stock and hence raise the real rate of interest.

To understand the differential behaviour of assets and capital per worker note that in standard models, capital is allocated in an efficient manner without frictions. Here, firms invest in capital stock prior to meeting a worker and this capital only becomes productive when successfully matched with a worker. Hence, there are really two types of capital backing net assets. ${ }^{20}$ First, as standard, there is capital that is productively matched that generates output and creates profits. Second, there is capital that has been used to create a vacancy but has yet to be productively employed since it is unmatched with a worker. Figure 1 shows an increase in unemployment benefits increases the value of matched capital but reduces the value of unmatched capital. The net result is the aggregate value of capital (and hence asset holdings) declines. Yet the level of capital per worker in productive job matches increases and the real interest rate decreases. In essence, the provision of public insurance in the form of unemployment benefits improves the efficiency of capital markets.

\footnotetext{
${ }^{19}$ There is no unemployment in a standard Aiyagari model and capital is equally divided between workers. As a result aggregate assets and capital per worker will always co-move positively. In Krusell, Muyokama and Şahin (2010), employment may vary due to labour market frictions. Hence, aggregate assets and capital per worker are not restricted to co-move positively, but they do in their numerical simulations describing the effect of changes in unemployment benefits. See Figure 2 and 4 of Mukoyama (2013) for an example in which capital and capital per worker move in opposite directions along a transition path.

${ }^{20}$ This is reflected in equation (12) where the value of assets depends upon both the value of vacancies created by firms as well as the expected future value of profits of matched firms.
} 


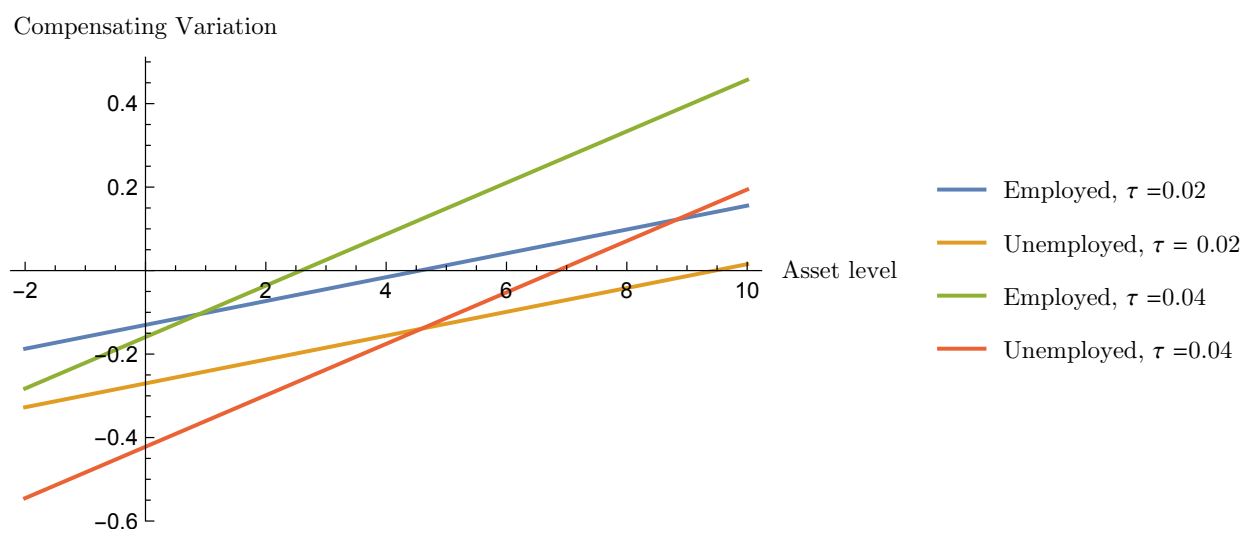

Figure 2: Compensating variation for employed and unemployed workers when moving from $\tau=0$ to a $\tau=0.02$ and from $\tau=0$ to $\tau=0.04$.

To understand the behaviour of the real interest rate consider the goods market and assume interest rates are fixed. On the supply side, an increase in unemployment benefits raises output net of investment due to the effect highlighted by Acemoglu and Shimer (1999). On the other hand, an increase in unemployment benefits leads to an increase in consumption since with greater unemployment insurance workers are willing to consume a greater amount. For our calibration, the increase in consumption exceeds the increase in output net of investment. Hence, to maintain an equilibrium in the goods market requires a fall in the real interest rate which increases vacancy creation and output more than consumption and investment.

To evaluate welfare we construct the compensating variation required to make workers indifferent to a policy change. Note that our measure of welfare varies from previous studies such as Pollak (2007) or Krusell, Mukoyama and Şahin (2010). Pollak (2007) examines the welfare of newly born individuals while Krusell, Mukoyama and Şahin (2010) and Lifschitz, Setty and Yedid-Levi (2016) calculate the percentage change in baseline consumption required to yield the same utility as a policy change for each individual and take the average of these values as a measure of welfare. In a representative agent framework this provides a direct measure of welfare but it is more difficult to interpret in a heterogeneous agent model where the percentage change in consumption required to compensate an individual may be correlated with consumption levels. In contrast, our compensating variation is a direct measure of the amount of resources a government would require to compensate individuals for a policy change.

To calculate the compensating variation, consider a worker in a particular employment state $i$, with asset level $a$ in an equilibrium without unemployment benefits. If we transferred this individual to an economy with positive unemployment benefits we can calculate the lump sum transfer (or tax) that would make this individual indifferent between his initial environment (with zero unemployment benefits) and his new environment (with positive unemployment benefits). Formally, we extend our notation to let $V_{i, j}(a ; \tau)$ to 


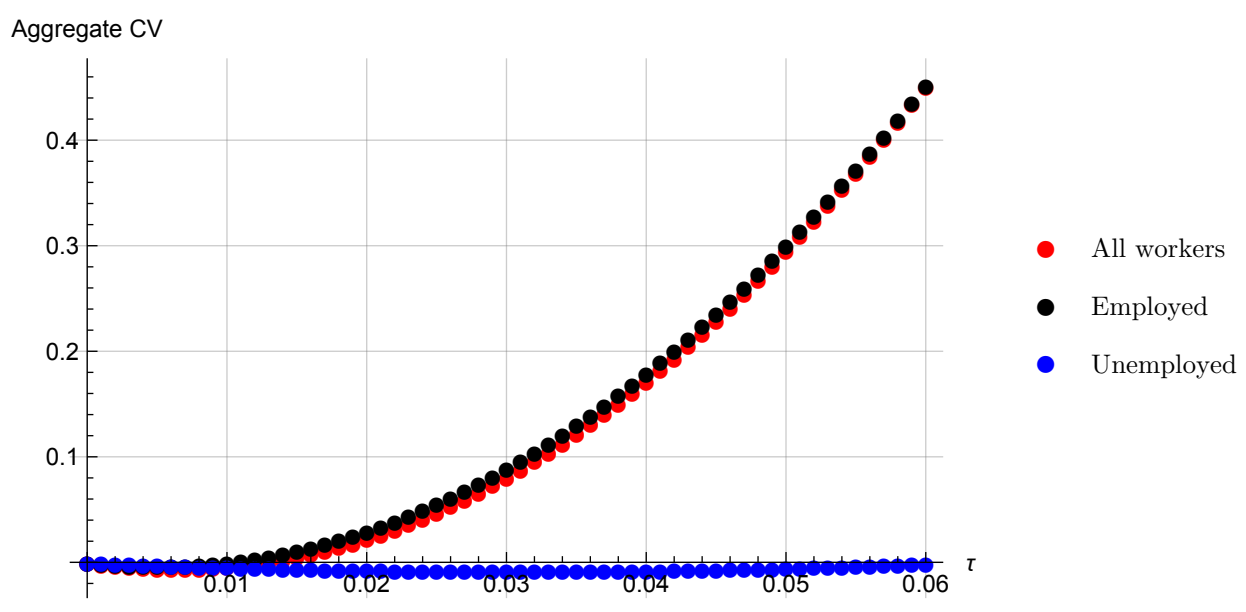

Figure 3: Aggregate transfer required to compensate individuals moving from an economy without unemployment benefits to an economy with benefits funded by a tax of $\tau$.

describe the expected discounted present value of future utility of an individual of type $j$ with employment status $i \in\{e, u\}$ and asset level $a$ in the steady state of an economy with income tax rate $\tau$. Then the compensating variation of moving a worker of type $j$ in employment state $i$ with $\tau=\tau_{0}$ to one in which $\tau=\tau_{1}$ is defined as $c v_{i, j}\left(a, \tau_{0}, \tau_{1}\right)$ :

$$
V_{i, j}\left(a ; \tau_{0}\right)=V_{i, j}\left(a+c v_{i, j}\left(a, \tau_{0}, \tau_{1}\right), \tau_{1}\right) .
$$

Explicitly, given our value functions,

$$
\begin{aligned}
c v_{i, j}\left(a, \tau_{0}, \tau_{1}\right)=\frac{1}{r_{f, \tau_{1}}+d} & \left(-\frac{1}{\gamma} \log \left(\frac{r_{f, \tau_{1}}+d}{r_{f, \tau_{0}}+d}\right)+b_{i, j}\left(\tau_{0}\right)-b_{i, j}\left(\tau_{1}\right)+\frac{\rho-r_{f, \tau_{0}}}{\gamma\left(r_{f, \tau_{0}}+d\right)}-\frac{\rho-r_{f, \tau_{1}}}{\gamma\left(r_{f, \tau_{1}}+d\right)}\right) \\
+ & \left(\frac{r_{f, \tau_{0}}-r_{f, \tau_{1}}}{r_{f, \tau_{1}}+d}\right) a
\end{aligned}
$$

where $r_{f, \tau_{j}}$ denotes the steady state interest rate firms face under unemployment benefits plan $\tau_{j}$ and $b_{i, j}\left(\tau_{j}\right)$ denotes the value of $b_{i, j}$ implied by equations (2) and (3) under unemployment benefits plan $\tau_{j}$. Note, for a given benefit levels $\tau_{0}$ and $\tau_{1}$, the compensating variation is simply linear in the asset level. Figure 2 displays the relationship between asset levels and compensating variation when moving from zero unemployment benefits to an economy with $\tau=0.02$ and to an economy with $\tau=0.04$. Unsurprisingly, employed workers require greater compensation than unemployed workers. Furthermore, workers with more assets require greater compensation since the interest rate declines as the size of unemployment benefits increase.

An interesting case to examine is when the interest rate is unchanged following a policy change. This occurs in settings with exogenous interest rates, as in Acemoglu and Shimer (1999). In that case the compensating variation simplifies to

$$
\frac{1}{r_{f}+d}\left(b_{i, j}\left(\tau_{0}\right)-b_{i, j}\left(\tau_{1}\right)\right) .
$$


Table 6: Decomposition of Compensating Variation

\begin{tabular}{lcc}
\hline \hline$\tau$ & CV holding $r_{f}$ fixed & Total CV \\
\hline 0.00 & 0.00 & 0.00 \\
0.01 & -0.033 & -0.004 \\
0.02 & -0.040 & 0.022 \\
0.03 & -0.021 & 0.080 \\
0.04 & 0.025 & 0.171 \\
0.05 & 0.097 & 0.295 \\
0.06 & 0.193 & 0.451 \\
\hline \multicolumn{2}{l}{ The second column is the aggregate compensating variation required in moving } \\
from $\tau=0$ to a positive $\tau$ assuming interest rates are unchanged. The third \\
column is the aggregate compensating variation.
\end{tabular}

We integrate the individual compensating variation with respect to the steady state distribution of assets under our initial equilibrium $\left(\tau_{0}=0\right)$ to find the aggregate transfer needed to compensate all agents for different values of $\tau_{1}$. The results of this exercise are displayed in Figure 3. We calculate the amount required to compensate employed and unemployed individuals separately, as well as in aggregate. For low values of $\tau$ the aggregate compensating variation is negative; that is, if lump sum transfers were available, workers could be compensated for a small increase in unemployment benefits and the government would have funds left over. But even at a moderate level of unemployment benefits, such as $\tau=0.013$ which corresponds to a replacement rate of 23 per cent, the aggregate compensating variation is positive implying that the government would have to raise funds to compensate workers. The optimal level of $\tau$, at least in terms of minimising the aggregate compensating variation, is a value of 0.006 which corresponds to a replacement rate of 11 per cent which is well below estimates of the replacement rate for the US economy.

Acemoglu and Shimer (1999) consider a similar setting but with fixed interest rates. In our setting, unemployment benefits affect the income associated with each state, the transition rates between states and the aggregate interest rate. The first two effects are present in Acemoglu and Shimer (1999) but the third effect is absent. Hence, we decompose the compensating variation into two components. First, how much would be needed to compensate individuals if interest rates remained unchanged but matching rates and income flows varied as a result of implementing an unemployment benefit system of $\tau>0$. The second component looks at how the changes in interest rates affect the compensating variation. The results are shown in Table 6 . The total payment required to compensate workers moving to an unemployment benefits system with a positive tax level is negative only for the small unemployment benefits. However, if the interest rate is exogenously fixed the minimum compensating variation occurs when $\tau=0.018$ and the corresponding replacement rate is approximately 35 per cent.

Considering an endogenous interest rate leads to significant changes in welfare implications. The introduction of unemployment benefits lowers the equilibrium interest rate. This is a positive outcome for debtors but detrimental to individuals with a large positive asset position. In steady state, a majority of individuals have 
Table 7: Response to unemployment benefits in economy with heterogeneous workers

\begin{tabular}{ccccccccc}
\hline \hline$\tau$ & Benefit rate & $w$ & $w$ & $u$ & $u$ & $k$ & $k$ & $r$ \\
& & Type I & Type II & $\begin{array}{c}u \\
\text { Type I }\end{array}$ & $\begin{array}{c}\text { Type II } \\
\text { Type I }\end{array}$ & $\begin{array}{c}\text { Type II } \\
\end{array}$ & \\
\hline 0.00 & 0.00 & 1.278 & 0.751 & 2.8 & 5.9 & 6.62 & 2.87 & 0.0454 \\
0.01 & 0.21 & 1.287 & 0.757 & 3.0 & 6.3 & 6.73 & 2.94 & 0.0447 \\
0.02 & 0.39 & 1.295 & 0.764 & 3.3 & 6.8 & 6.85 & 3.00 & 0.0439 \\
0.03 & 0.53 & 1.304 & 0.770 & 3.5 & 7.4 & 6.96 & 3.06 & 0.0432 \\
0.04 & 0.64 & 1.311 & 0.775 & 3.9 & 8.1 & 7.06 & 3.11 & 0.0425 \\
0.05 & 0.73 & 1.318 & 0.780 & 4.3 & 8.8 & 7.15 & 3.16 & 0.0419 \\
\hline
\end{tabular}

accumulated significant asset holdings. As a result, the welfare implications of interest rate fluctuations are substantial.

\section{Unemployment Benefits with Heterogeneous Workers}

We conduct a similar exercise with our heterogeneous worker calibration. In this setting workers differ in their characteristics so unemployment benefits are a means of (i) providing insurance to negate the effect of labour market shocks but also (ii) redistributing income from more skilled to less skilled workers.

Table 7 shows how the endogenous variables in an economy respond to an increase in unemployment benefits. As in the previous case, unemployment, wages and the capital-labour ratio rise for both skilled and unskilled workers while the interest rate declines. We also examine the effect of unemployment benefits on welfare. Figure 4 shows the required compensation of moving from an economy without benefits to a system where $\tau=0.02$ for workers in different states. The compensating variation depends upon worker type, employment status and asset holdings. Unsurprisingly, holding wealth constant, skilled workers require more compensation than unskilled workers. Also conditional upon worker type and wealth, unemployed workers require less compensation for the policy change. Finally, the level of compensation is increasing in asset holdings. This reflects, as in the homogeneous case, the decline in the interest rate reduces asset income and consumption.

As before, we calculate the aggregate compensating variation by integrating over the distribution of workers. The results for changing from a system with zero unemployment benefits to a system with positive $(\tau>0)$ benefits are displayed in Figure 5. A number of observations are in order. In this case, value of unemployment benefits that minimises the aggregate compensating variation is essentially zero. ${ }^{21}$ This implies that moving away from zero benefits requires a positive net transfer into the economy to compensate all individuals. This occurs even though in the heterogeneous worker economy unemployment benefits fulfill two roles: it provides insurance against labour market shocks and redistributes income from the more to the less skilled.

\footnotetext{
${ }^{21}$ For the smallest value of unemployment benefits that we consider, $\tau=0.001$ which has an associated benefit level of $b=0.02$ we find that the net compensating variation is positive.
} 


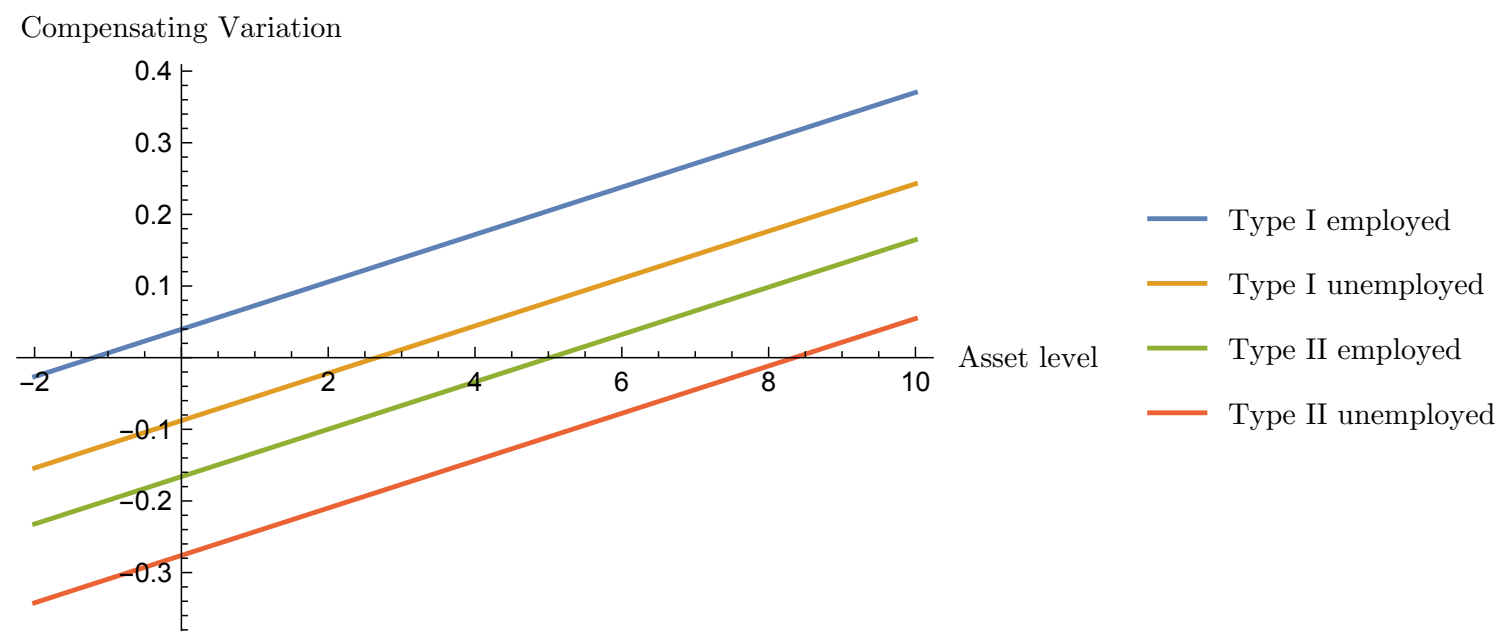

Figure 4: Compensating variation associated with moving from zero unemployment benefits to $\tau=0.2$

Employment opportunities vary across groups so it is unsurprising that the welfare implications of unemployment benefits vary by worker type. In aggregate, unskilled workers gain more (or lose less) from the imposition of unemployment benefits. Aggregating over only unskilled workers, the compensating variation is minimised when $\tau=0.011$ which corresponds to a benefit level of $b=0.23$. On the other hand, skilled workers as a group require positive net transfers to compensate them for the introduction of a system with even small transfers.

We also evaluate how welfare implications would change if the interest rate is exogenously maintained at its initial value. That is, we vary $\tau$ and solve for equilibrium using equations (1) - (10) while maintaining $r_{f}$ fixed at its initial equilibrium value. In this case the tax rate that minimises the aggregate compensating variation is $\tau=0.01$ which corresponds to a replacement rate of 21 per cent. Again, different workers types would prefer different benefit systems. In particular, the minimum aggregate compensating variation for skilled workers still occurs when $\tau=0$ while for unskilled workers, the minimum aggregate compensating variation occurs when $\tau=0.033$ which corresponds to a replacement rate of 0.56 . Hence, the failure of even modest levels of unemployment benefits to generate negative aggregate compensating variation arises, again, due to the endogenous response of interest rates to the introduction of unemployment benefits. The interest rate declines and interest income is, for most people, a valuable source of income.

Note that in contrast to Lifschitz Setty and Yedid-Levi (2016), we find that the introduction of heterogeneity lowers the optimal insurance replacement rates rather than raises it. We make a few comments regarding this result. First, our model differs from Lifschitz Setty and Yedid-Levi (2016) along a number of dimensions. Our model features a directed search environment with capital being allocated prior to the formation of a job match while they examine a setting with bargaining and capital allocated after jobs are created. In 


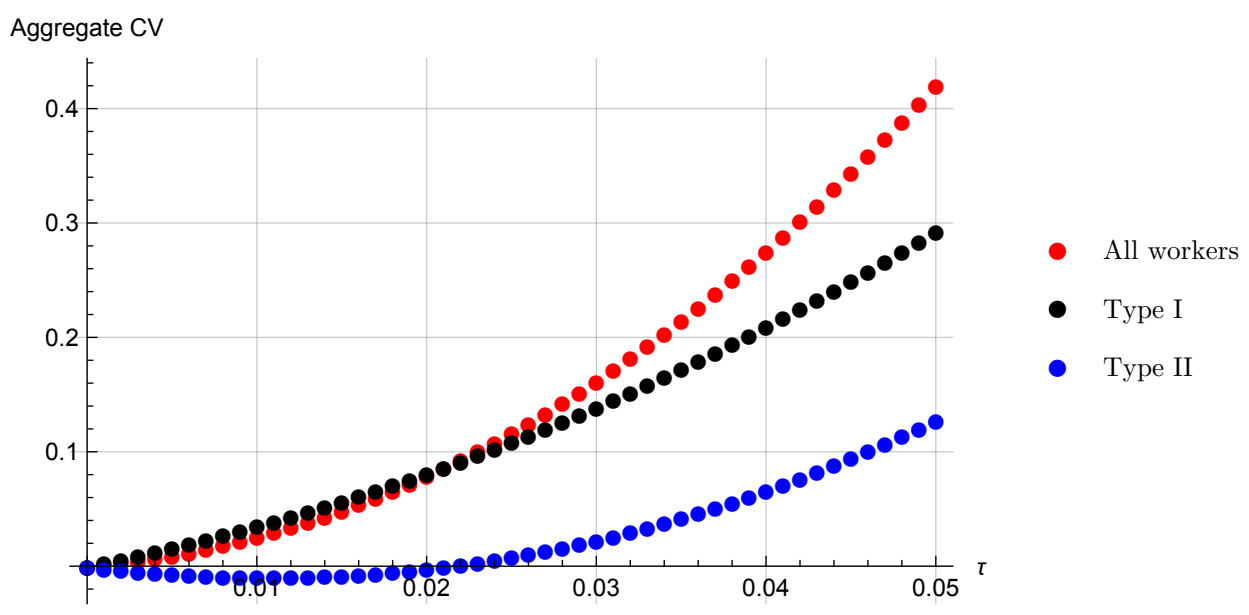

Figure 5: Aggregate compensating variation by worker type and total.

addition, we use CARA utility while they focus upon CRRA utility. Second, our result that heterogeneity reduces the optimal replacement rate does depend upon the calibration. For example, if we consider a parameterisation in which productivity levels are 15 per cent higher for both types of workers, we find that the model does almost as well as in matching our data targets and that the optimal replacement rate is similar across homogeneous and heterogeneous settings. ${ }^{22}$ Finally, the welfare measures considered differ. Ours is a measure of the resource cost associated with compensating individuals for a change in policy. Theirs examines the average percentage change in consumption required to yield the same utility as a change in unemployment insurance policy. For each individual they calculate the percentage change in baseline consumption that would be equivalent to introducing unemployment insurance and then calculate the average of these percentage changes. Skilled workers with high consumption levels and low unemployment typically lose from unemployment insurance since although they receive unemployment benefits they also subsidise workers with high unemployment rates. On the other hand, unskilled workers with low consumption levels typically gain by receiving insurance that is subsidised by skilled workers. As a result, taking the average of percentage change in consumption that leads to equivalent welfare will not be an accurate measure of the resource cost of compensating individuals since the percentage change of consumption equivalence is correlated with consumption levels in a systematic manner.

\section{Alternative Unemployment Insurance Systems}

As noted in the introduction there are a variety of unemployment insurance systems. In this section we examine how different unemployment insurance systems affect economic outcomes. As an alternative, we

\footnotetext{
${ }^{22}$ Details of this alternate calibration are available from the author upon request. The higher productivity level raises the cost of unemployment and raises the optimal replacement rate. It only slightly worsens the match between data and model by altering unemployment rates.
} 
consider an unemployment insurance system that is funded by a proportional tax on labour income (as in Section 2) but provides unemployed workers with a lump-sum payment that is not linked to previous wage income.

Our basic environment remains unchanged except that when a worker of type $j$ is unemployed they receive $y_{u, j}=B$ where $B$ reflects a lump sum benefit that is constant and independent of previous wages or worker types. This small modification only has a limited impact upon our key equations that describe labour market equilibrium. Equations (1) - (8) and equation (10) and (11) continue to hold except with $y_{u, j}=B$ rather than $b \cdot w$. The equation that describes budget balance is altered so that

$$
\sum_{j} u_{j} B=\sum_{j} \tau w_{j}\left(\pi_{j}-u_{j}\right)
$$

In a model with homogeneous workers, the difference in the redistribution schemes (lump sum or proportional) has no effect on aggregate outcomes. For the same tax rate, $\tau$, the implications upon economic outcomes are identical and the unemployment insurance payment that balances the budget is also identical. $^{23}$

The key difference in these unemployment insurance systems occurs in settings with heterogeneous workers, which will be the focus of our analysis. In these settings, the differences in unemployment insurance payments results in different levels of redistribution. With unemployment insurance payments proportional to previous income, high skilled workers receive relatively large unemployment benefits compared to low skilled workers. On the other hand, with lump sum payments, high skilled workers receive the same amount as a low skilled worker when unemployed. In this case, there is a greater amount of redistribution.

Table 8 outlines the equilibrium outcomes under a unemployment insurance system with lump sum benefits for different levels of taxation. The qualitative behaviour of the model is unchanged from our baseline model discussed in Section 5 and presented in Table 7. As tax rates rise, wages, capital-laobur ratios and unemployment for both types tend to increase. There is also a decline in the real interest rate. From a quantitative perspective the most notable difference occurs in the response of the unemployment rate to tax rates. Figure 6 shows the change in unemployment for each worker type (relative to the baseline) for both unemployment insurance systems. In the setting with unemployment benefits proportional to income, an increase in benefits generates a similar percentage change in unemployment for both worker types. On the other hand, with lump sum benefits we find that an increase in the size of the unemployment insurance system, increases the unemployment rate of unskilled workers by a large amount relative to skilled workers.

We also examine the welfare implications of a lump sum benefit. To do so, we follow our earlier approach and

\footnotetext{
${ }^{23} \mathrm{~A}$ formal proof of the equivalence of outcomes in the homogenous setting is available from the author on request. We retain the assumption that when firms set wages, they adjust $w$ realising that this impacts the utility of unemployed workers through future wages but does not affect the level of unemployment insurance payments.
} 

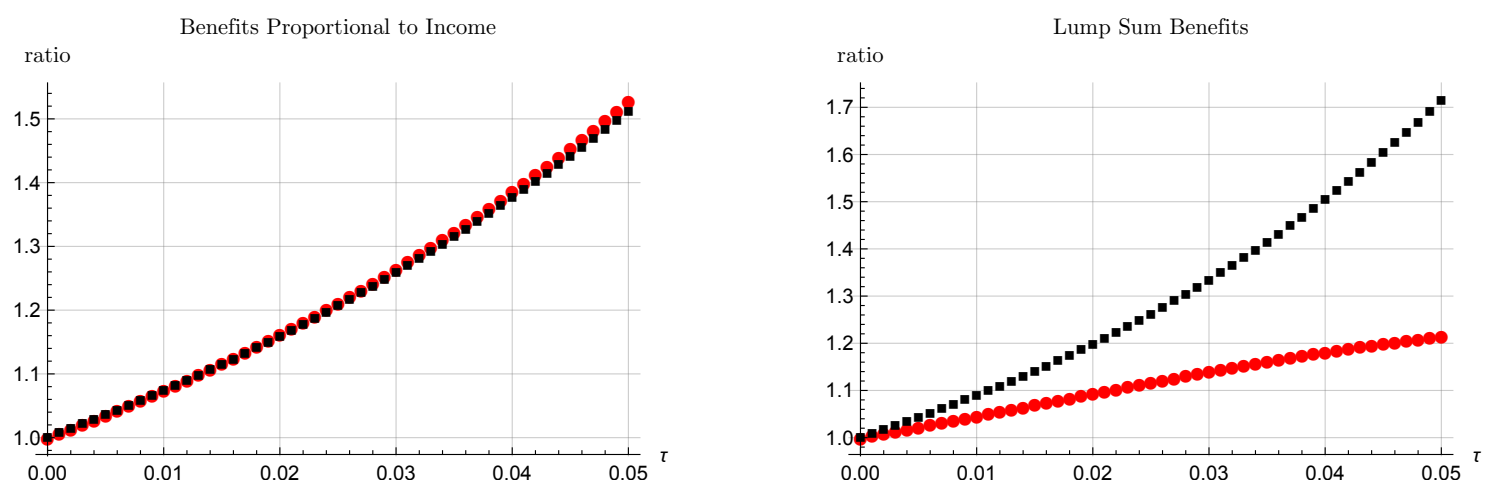

Figure 6: Unemployment response to changes in $\tau$ under different unemployment insurance schemes. The left hand panel displays unemployment outcomes as $\tau$ varies in a system with unemployment benefits proportional to income. The right panel displays unemployment outcomes as $\tau$ varies in a system with lump sum unemployment benefits. Red dots represent outcomes of skilled workers. Black dots represent outcomes of unskilled workers. Unemployment for each type in baseline model normalised to one.

Table 8: Response to unemployment benefits with lump sum benefits

\begin{tabular}{ccccccccc}
\hline \hline$\tau$ & Benefit level & $w$ & $w$ & $u$ & $u$ & $k$ & $k$ & $r$ \\
& & Type I & Type II & Type I & $\begin{array}{c}u \\
\text { Type II }\end{array}$ & $\begin{array}{c}\text { Type I } \\
\text { Type II }\end{array}$ & \\
\hline 0.00 & 0.00 & 1.278 & 0.751 & 2.8 & 5.9 & 6.62 & 2.87 & 0.0454 \\
0.01 & 0.19 & 1.285 & 0.758 & 2.9 & 6.4 & 6.72 & 2.95 & 0.0446 \\
0.02 & 0.34 & 1.293 & 0.765 & 3.1 & 7.0 & 6.81 & 3.01 & 0.0440 \\
0.03 & 0.47 & 1.300 & 0.771 & 3.2 & 7.8 & 6.91 & 3.08 & 0.0433 \\
0.04 & 0.56 & 1.306 & 0.777 & 3.3 & 8.8 & 6.99 & 3.13 & 0.0423 \\
0.05 & 0.63 & 1.311 & 0.781 & 3.4 & 10.0 & 7.06 & 3.18 & 0.0422 \\
\hline
\end{tabular}




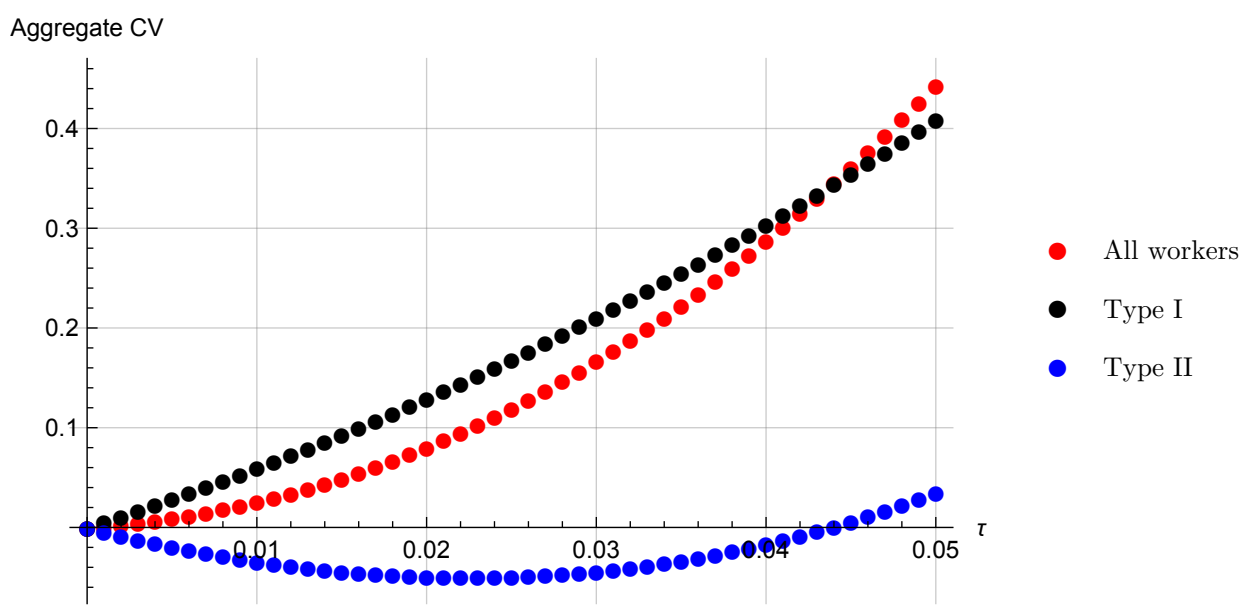

Figure 7: Aggregate compensating variation by worker type and total with lump sum benefits.

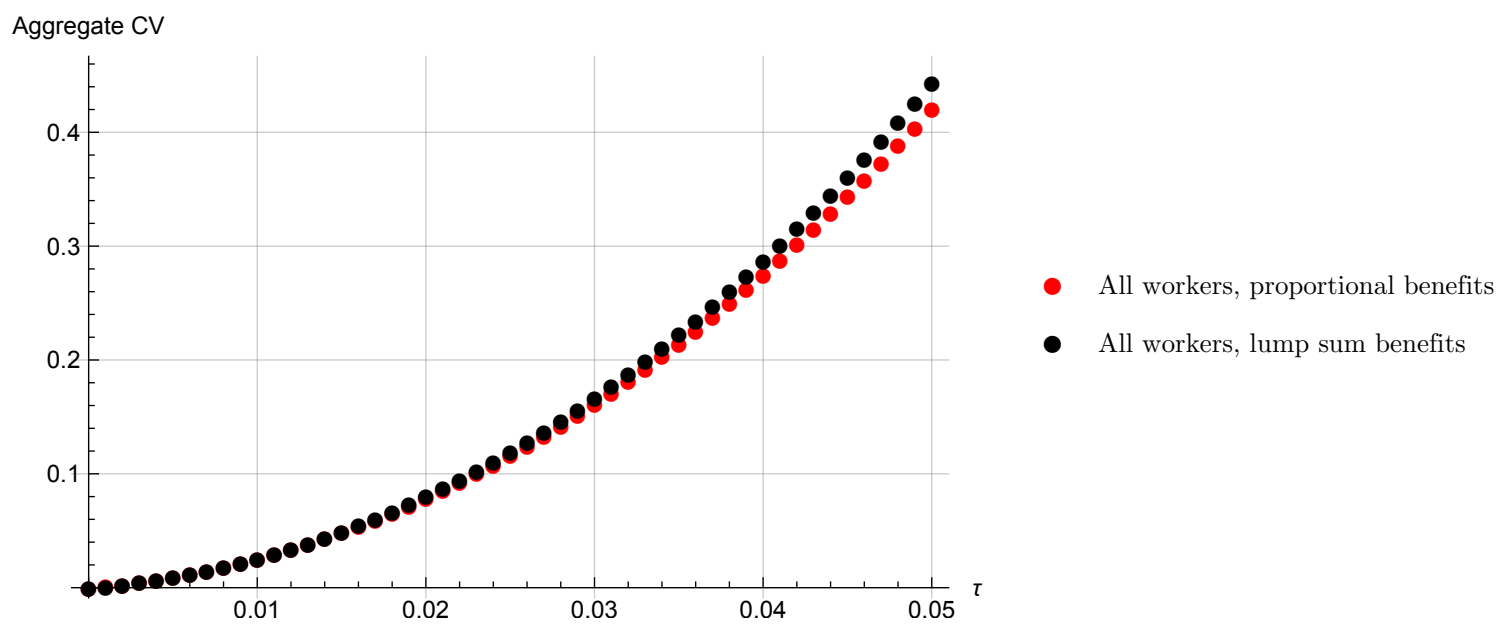

Figure 8: Aggregate compensating variation as $\tau$ varies for alternative unemployment insurance systems.

calculate the compensating variation for each worker type and integrate with respect to the distribution of worker types and asset holdings. A comparison between an unemployment insurance system with lump sum benefits relative to a system with proportional benefits is shown in Figure 8. We again find that the aggregate compensating variation is minimised with a tax rate of zero and the potential differences between welfare systems is small. At higher rates of unemployment insurance, it becomes apparent that the unemployment insurance systems with proportional benefits yield slightly smaller welfare losses. Although we don't present the results here in full, the similarity in welfare results across unemployment insurance systems also applies to settings with fixed interest rates. In particular, with fixed interest rates, we find that with lump sum benefits the minimum compensating variation is negative and occurs at approximately the same level of $\tau$ as in the proportional system. Furthermore, the value of the minimum aggregate compensating variation is very similar across different unemployment insurance systems. 


\section{Conclusion}

This paper has constructed a continuous time model with a frictional labour market and incomplete financial market. It uses this framework to examine the possibility that motives for redistribution may increase the optimal level of unemployment benefits. By examining the difference between a model in which workers are ex ante homogeneous to one in which workers are heterogeneous we find little role for redistribution in increasing unemployment benefits, at least when we evaluate welfare using a compensating variation approach.

There are two key mechanisms present in our setting that are absent in the previous literature. First, our model features a directed search environment so that changes in unemployment benefits affect the optimal search behaviour of participants in the labour market. As in Acemoglu and Shimer (1999), this leads to more productive jobs being created in equilibrium. Second, our model features an equilibrium in the goods market with changes in unemployment benefits affecting the equilibrium interest rate. The inclusion of the endogenous response of interest rates to unemployment benefits reduces the optimal level of insurance in this economy.

We also use the model to evaluate differences in unemployment insurance systems across countries. Some countries pursue a system in which the payment of benefits is linked to previous labour income. In other regions of the world, unemployment benefits are lump sum transfers that are independent of past labour market history. In our analysis, the welfare effects of these policies are similar. There are differences in outcomes, most notably the response of unemployment to the provision of insurance varies across worker groups if benefits are paid in a lump sum fashion.

\section{Appendix}

\subsection{Proof of Proposition 1}

The proof uses the "guess and verify" methodology. Following Shimer and Werning (2007) or Wang (2007) we may conjecture the value function has the following form,

$$
V_{i, j}(a)=\frac{-e^{-\gamma\left(r \cdot a+b_{i, j}+\frac{\rho+d-r}{\gamma r}\right)}}{r}
$$

with $b_{i, j}$ an undetermined coefficient that depends upon employment status $i$ for worker $j$. The following Bellman equations describe recursively the value for a worker who is employed, $V_{e, j}(a)$, and for an unemployed 
worker, $V_{u, j}(a)$ :

$$
\begin{aligned}
& \rho V_{u, j}(a)=\max _{c_{u, j}(a)}\left\{u\left(c_{u, j}(a)\right)+V_{u, j}^{\prime}(a)\left(r \cdot a+y_{u, j}-c_{u, j}(a)\right)+\lambda_{j}\left(V_{e, j}(a)-V_{u, j}(a)\right)+d\left(0-V_{u, j}(a)\right)\right\} \\
& \rho V_{e, j}(a)=\max _{c_{e, j}(a)}\left\{u\left(c_{e, j}(a)\right)+V_{e, j}^{\prime}(a)\left(r \cdot a+y_{e, j}-c_{e, j}(a)\right)+\delta\left(V_{u, j}(a)-V_{e, j}(a)\right)+d\left(0-V_{e, j}(a)\right)\right\}
\end{aligned}
$$

The first order condition associated with this problem yields:

$$
\begin{aligned}
u^{\prime}\left(c_{i, j}(a)\right) & =V_{i, j}^{\prime}(a) \\
\gamma e^{-\gamma c_{i, j}} & =V_{i, j}^{\prime}(a)=\left(\gamma r \cdot \frac{e^{\left.-\gamma r a+b_{i, j}+\frac{\rho+d-r}{\gamma r}\right)}}{r}\right) \\
\rightarrow \gamma e^{-\gamma c_{i, j}} & =\gamma e^{-\gamma\left(r a+b_{i, j}+\frac{\rho+d-r}{\gamma r}\right)}
\end{aligned}
$$

Which implies a value for $c_{i, j}(a)=r \cdot a+b_{i, j}+\frac{\rho+d-r}{\gamma r}$. Substituting this into our Bellman equations and simplifying implies the initial guess will satisfy our Bellman equation if (2) and (3) hold.

To show that a unique solution exists for the system of (2) and (3) let,

$$
\begin{aligned}
& f\left(b_{e, j}, b_{u, j}\right)=\left(\gamma r\left(y_{u, j}-b_{u, j}\right)+\lambda_{j}\right) e^{-\gamma b_{u, j}}-\lambda e^{-\gamma b_{e, j}} \\
& g\left(b_{e, j}, b_{u, j}\right)=\left(\gamma r\left(y_{e, j}-b_{e, j}\right)+\delta\right) e^{-\gamma b_{e, j}}-\delta e^{-\gamma b_{u, j}}
\end{aligned}
$$

Define the function

$$
b_{u, j}^{*}\left(b_{e, j}\right)=-\frac{1}{\gamma} \log \left(\frac{\gamma r\left(y_{e, j}-b_{e, j}\right)}{\delta}+1\right)+b_{e, j}
$$

By construction $g\left(b_{e, j}, b_{u, j}^{*}\left(b_{e, j}\right)\right)=0$.

$$
\begin{aligned}
& b_{u, j}^{*}\left(y_{u, j}\right)=-\frac{1}{\gamma} \log \left(\frac{\gamma r\left(y_{e, j}-y_{u, j}\right)}{\delta}+1\right)+y_{u, j}<y_{u, j} \\
& b_{u, j}^{*}\left(y_{e, j}\right)=-\frac{1}{\gamma} \log \left(\frac{\gamma r\left(y_{e, j}-y_{e, j}\right)}{\delta}+1\right)+y_{e, j}=y_{e, j}
\end{aligned}
$$

Define

$$
h\left(b_{e, j}\right)=f\left(b_{e, j}, b_{u, j}^{*}\left(b_{e, j}\right)\right)=\left(\gamma r\left(y_{u, j}-b_{u, j}^{*}\left(b_{e, j}\right)\right)+\lambda_{j}\right) e^{-\gamma b_{u, j}^{*}\left(b_{e, j}\right)}-\lambda_{j} e^{-\gamma b_{e, j}}
$$

Note $h\left(y_{u, j}\right)=f\left(y_{u, j}, b_{u, j}^{*}\left(y_{u, j}\right)\right)>f\left(y_{u, j}, y_{u, j}\right)=0$ since $f$ is decreasing in its second argument. And $h\left(y_{e, j}\right)=f\left(y_{e, j}, b_{u, j}^{*}\left(y_{e, j}\right)\right)=f\left(y_{e, j}, y_{e, j}\right)<0$. The function is also clearly continuous so by the intermediate value theorem, we know that $h(x)=0$ for some $y_{u, j}<x<y_{e, j}$. Hence, $\left(x, b_{u, j}^{*}(x)\right)$ is a solution to $\left(b_{e, j}, b_{u, j}\right)$ that solves (2) and (3) exists.

For uniqueness, we can use a single-crossing property by showing that at any intersection the derivative of the curves are always such that they will only cross once. Use the implicit function theorem on both $f$ and $g$ to find $\frac{d b_{u, j}}{d b_{e, j}}$. 
Along $f=0$,

$$
\begin{array}{r}
\lambda_{j} \gamma e^{-\gamma b_{e, j}} d b_{e, j}+\left(-\gamma r e^{-\gamma b_{u, j}}-\gamma\left(\gamma r\left(y_{u, j}-b_{u, j}\right)+\lambda_{j}\right) e^{-\gamma b_{u, j}}\right) d b_{u, j}=0 \\
\rightarrow \frac{d b_{u, j}}{d b_{e, j}}=\frac{\lambda_{j} e^{-\gamma b_{e, j}}}{r e^{-\gamma b_{u, j}}+\left(\gamma r\left(y_{u, j}-b_{u, j}\right)+\lambda_{j}\right) e^{-\gamma b_{u, j}}}
\end{array}
$$

Along $g=0$

$$
\begin{array}{r}
-\gamma r e^{-\gamma b_{e, j}}-\gamma\left(\gamma r\left(y_{e, j}-b_{e, j}\right)+\delta\right) e^{-\gamma b_{e, j}} d b_{e, j}+\delta \gamma e^{-\gamma b_{u, j}} d b_{u, j} \\
\rightarrow \frac{d b_{u, j}}{d b_{e, j}}=\frac{r e^{-\gamma b_{e, j}}+\left(\gamma r\left(y_{e, j}-b_{e, j}\right)+\delta\right) e^{-\gamma b_{e, j}}}{\delta e^{-\gamma b_{u, j}}}
\end{array}
$$

Note that for any point that satisfies $f=g=0$ that

$$
\frac{r+\gamma r\left(y_{e, j}-b_{e, j}\right)+\delta}{\delta}>\frac{\lambda_{j}}{r+\gamma r\left(y_{u, j}-b_{u, j}\right)+\lambda_{j}}
$$

because our equilibrium consumption conditions imply

$$
\frac{\gamma r\left(y_{e, j}-b_{e, j}\right)+\delta}{\delta}=\frac{\lambda_{j}}{\gamma r\left(y_{u, j}-b_{u, j}\right)+\lambda_{j}}
$$

This implies that at any equilibrium the slopes of the lines will always be ordered in the same manner.

It is straightforward to see, that the transversality condition will also be satisfied by this consumption rule for any $r>0$. Explicitly, assets decline, at most, at a linear rate and discounting occurs at an exponential rate. This guarantees $\lim _{t \rightarrow \infty} e^{-r t} a_{t}=0$

To show that $b_{e, j}>b_{u, j}$, we use proof by contradiction. Assume $b_{u, j}>b_{e, j}$. We can write our relevant system as

$$
\begin{aligned}
& \gamma r\left(y_{u, j}-b_{u, j}\right)=\lambda_{j}\left(e^{-\gamma\left(b_{e, j}-b_{u, j}\right)}-1\right) \\
& \gamma r\left(y_{e, j}-b_{e, j}\right)=\delta\left(e^{-\gamma\left(b_{u, j}-b_{e, j}\right)}-1\right)
\end{aligned}
$$

Then $y_{e, j}>y_{u, j}$ and $b_{u, j}>b_{e, j}$ (by assumption), implies $\gamma r\left(y_{u, j}-b_{u, j}\right)<\gamma r\left(y_{e, j}-b_{e, j}\right)$. But examining the right-hand side of the above equations, using $b_{u, j}>b_{e, j}$ implies that

$$
\begin{aligned}
\lambda\left(e^{-\gamma\left(b_{e, j}-b_{u, j}\right)}-1\right) & >0 \\
\delta\left(\left(e^{-\gamma\left(b_{u, j}-b_{e, j}\right)}-1\right)\right) & <0
\end{aligned}
$$

which implies that $\gamma r\left(y_{u, j}-b_{u, j}\right)>\gamma r\left(y_{e, j}-b_{e, j}\right)$ contradicting the earlier result. Hence, the assumption $b_{u, j}>b_{e, j}$ is false. 


\subsection{Proof of Proposition 2}

Let $s_{e, j}=y_{e, j}-b_{e, j}-\frac{\rho+d-r}{\gamma r}$ and $s_{u, j}=y_{u, j}-b_{u, j}-\frac{\rho+d-r}{\gamma r}$. For $a<0$, the differential equation describing $F_{j}$ and $G_{j}$ can be rewritten: The differential equation can be written in the following form,

$$
\left(\begin{array}{c}
F_{j}^{\prime}(a) \\
G_{j}^{\prime}(a)
\end{array}\right)=\left(\begin{array}{cc}
-\frac{\delta_{j}+d}{s_{e, j}} & \frac{\lambda_{j}}{s_{e, j}} \\
\frac{\delta_{j}}{s_{u, j}} & -\frac{\lambda_{j}+d}{s_{u, j}}
\end{array}\right)\left(\begin{array}{c}
F_{j}(a) \\
G_{j}(a)
\end{array}\right)
$$

This is a standard homogeneous linear system with constant coefficients and boundary conditions that $\lim _{a \rightarrow-\infty} F_{j}(a)=\lim _{a \rightarrow-\infty} G_{j}(a)=0$. The eigenvalues of

$$
\left(\begin{array}{cc}
-\frac{\left(\delta_{j}+d\right)}{s_{e, j}} & \frac{\lambda_{j}}{s_{e, j}} \\
\frac{\delta}{s_{u, j}} & -\frac{\left(\lambda_{j}+d\right)}{s_{u, j}}
\end{array}\right)
$$

are the values of $\phi$ that solve the following characteristic equation

$$
\frac{s_{e, j} s_{u, j} \phi^{2}+\left(s_{u, j}\left(d+\delta_{j}\right)+s_{e, j}\left(d+\lambda_{j}\right)\right) \phi+d\left(d+\delta_{j}+\lambda_{j}\right)}{s_{e, j} s_{u, j}}=0
$$

This is equivalent to finding the values in which

$$
s_{e, j} s_{u, j} \phi^{2}+\left(s_{u, j}\left(d+\delta_{j}\right)+s_{e, j}\left(d+\lambda_{j}\right)\right) \phi+d\left(d+\delta_{j}+\lambda_{j}\right)=0
$$

With $s_{e, j}>0$ and $s_{u, j}<0$ there is guaranteed to be one positive and one negative eigenvalue. Let, without loss of generality, that $\phi_{1}>0$ and $\phi_{2}<0$. The general solution to such a system is

$$
\left(\begin{array}{c}
F_{j}(a) \\
G_{j}(a)
\end{array}\right)=C_{1}\left(\begin{array}{c}
\xi_{11} \\
\xi_{12}
\end{array}\right) e^{\phi_{1} a}+C_{2}\left(\begin{array}{c}
\xi_{21} \\
\xi_{22}
\end{array}\right) e^{\phi_{2} a}
$$

where

$$
\begin{aligned}
& \xi_{1}=\left(\begin{array}{l}
\xi_{11} \\
\xi_{12}
\end{array}\right) \\
& \xi_{2}=\left(\begin{array}{l}
\xi_{21} \\
\xi_{22}
\end{array}\right)
\end{aligned}
$$

are the eigenvectors that correspond to the first and second eigenvalue respectively. Straightforward calculations show,

$$
\begin{aligned}
\xi_{11} & =\frac{\lambda_{j}}{\delta_{j}+d+s_{e, j} \phi_{1}} \\
\xi_{21} & =\frac{\lambda_{j}}{\delta_{j}+d+s_{e, j} \phi_{2}}
\end{aligned}
$$

with $\xi_{12}$ and $\xi_{22}$ normalised to one. For the region where $a<0$ the boundary conditions imply $C_{2}=0$ since $\lim _{a \rightarrow-\infty} F_{j}(a)=\lim _{a \rightarrow-\infty} G_{j}(a)=0$.

$$
\left(\begin{array}{c}
F_{j}(a) \\
G_{j}(a)
\end{array}\right)=C_{1}\left(\begin{array}{c}
\xi_{11} \\
1
\end{array}\right) e^{\phi_{1} a}
$$


For the region where $a>0$, the differential equation is a standard non-homogeneous linear system. The general solution is,

$$
\left(\begin{array}{c}
F_{j}(a) \\
G_{j}(a)
\end{array}\right)=C_{1}\left(\begin{array}{c}
\xi_{11} \\
1
\end{array}\right) e^{\phi_{1} a}+C_{2}\left(\begin{array}{c}
\xi_{21} \\
\xi_{22}
\end{array}\right) e^{\phi_{2} a}+\left(\begin{array}{c}
C_{F} \\
C_{G}
\end{array}\right)
$$

with the restriction that $\phi_{1}>0$ implies $C_{1}=0$ since $\lim _{a \rightarrow \infty} F_{j}(a)$ and $\lim _{a \rightarrow \infty} G_{j}(a)$ are finite. Further,

$$
\begin{aligned}
C_{F} & =\frac{\pi_{j} \lambda_{j}}{\lambda_{j}+\delta_{j}+d} \\
C_{G} & =\frac{\pi_{j}\left(\delta_{j}+d\right)}{\lambda_{j}+\delta_{j}+d}
\end{aligned}
$$

since $C_{F}$ and $C_{G}$ reflect the total mass of workers in employment and unemployment respectively. Furthermore, as is standard in continuous drift models with resetting, there is no discountity so $\lim _{\epsilon \rightarrow 0} F_{j}(0-\epsilon)=$ $\lim _{\epsilon \rightarrow 0} F_{j}(0+\epsilon)$ and $\lim _{\epsilon \rightarrow 0} G_{j}(0-\epsilon)=\lim _{\epsilon \rightarrow 0} G_{j}(0+\epsilon)$. As a result,

$$
\begin{aligned}
C_{1} & =C_{2}+C_{G} \\
C_{1}\left(\frac{\lambda_{j}}{\delta_{j}+d+s_{e, j} \phi_{1}}\right) & =C_{2}\left(\frac{\lambda_{j}}{\delta_{j}+d+s_{e, j} \phi_{2}}\right)+C_{F}
\end{aligned}
$$

Which gives us enough information to pin down $\left(C_{1}, C_{2}\right)$ :

$$
\begin{aligned}
C_{2} & =\frac{\pi_{j} \phi_{1}\left(\delta_{j}+d+s_{e, j} \phi_{2}\right)}{\left(\delta_{j}+d+\lambda_{j}\right)\left(\phi_{2}-\phi_{1}\right)} \\
C_{1} & =C_{2}+\frac{\pi_{j}\left(\delta_{j}+d\right)}{\delta_{j}+d+\lambda_{j}}
\end{aligned}
$$

Straightforward integration reveals that aggregate asset holdings are

$$
A=\frac{1}{d}\left(\left(\pi_{j}-u_{j}\right)\left(y_{e, j}-b_{e, j}\right)+u_{j}\left(y_{u, j}-b_{u, j}\right)+\pi_{j} \cdot \frac{r-\rho-d}{\gamma r}\right)
$$

\subsection{Microeconomic Outcomes}

We explore the implications of the model on the equilibrium distribution of consumption and welfare. Proposition 2 describes the distribution of wealth in an economy with exogenous transition rates, and income for employed and unemployed workers. These transition rates and incomes are endogenised by imposing market equilibrium. Furthermore, since consumption and the Bellman value are functions of the asset level it is possible to derive the distribution of consumption and welfare. We consider an economy with only one worker type and suppress the subscript $j$ in what follows, but the extension to many worker types is straightforward. Let $g_{e}(c)$ be the probability mass function of consumption by employed workers and $g_{u}(c)$ be the corresponding function for unemployed workers. ${ }^{24}$

\footnotetext{
${ }^{24}$ Throughout the paper we work with cumulative mass functions and probability mass functions. These are the analogs of cumulative density and probability density functions except the probability mass function does not integrate to one and the cumulative mass function does not reach a maximum of one.
} 
Then a transformation of variables implies,

$$
\begin{array}{r}
g_{e}(c)= \begin{cases}f_{1}\left(\frac{1}{r}\left(c_{e}-b_{e}-\frac{\rho+d-r}{\gamma r}\right)\right) \frac{1}{r} & \text { if } c<b_{e}+\frac{\rho+d-r}{\gamma r} \\
f_{2}\left(\frac{1}{r}\left(c_{e}-b_{e}-\frac{\rho+d-r}{\gamma r}\right)\right) \frac{1}{r} & \text { if } c>b_{e}+\frac{\rho+d-r}{\gamma r}\end{cases} \\
g_{u}(c)= \begin{cases}g_{1}\left(\frac{1}{r}\left(c_{u}-b_{u}-\frac{\rho+d-r}{\gamma r}\right)\right) \frac{1}{r} & \text { if } c<b_{u}+\frac{\rho+d-r}{\gamma r} \\
g_{1}\left(\frac{1}{r}\left(c_{u}-b_{u}-\frac{\rho+d-r}{\gamma r}\right)\right) \frac{1}{r} & \text { if } c>b_{u}+\frac{\rho+d-r}{\gamma r}\end{cases}
\end{array}
$$

where $f_{1}(a)$ and $g_{1}(a)$ are the derivative of $F(a)$ and $G(a)$ when $a<0$ and $f_{2}(a)$ and $g_{2}(a)$ are the derivative of $F(a)$ and $G(a)$ when $a>0$ with $F$ and $G$ defined in Proposition 2. Similarly, let $h_{e}(v)$ and $h_{u}(v)$ represent the probability mass function of expected present discounted utility of employed workers and unemployed workers, respectively. Then,

$$
\begin{aligned}
& h_{e}(v)= \begin{cases}f_{1}\left(\frac{1}{r}\left(-\frac{1}{\gamma} \log (-r v)-b_{e}-\frac{\rho+d-r}{\gamma r}\right)\right) \frac{1}{\gamma r|v|} & \text { if } v<-\frac{e^{-\gamma\left(b_{e}+\frac{\rho+d-r}{\gamma r}\right)}}{r} \\
f_{2}\left(\frac{1}{r}\left(-\frac{1}{\gamma} \log (-r v)-b_{e}-\frac{\rho+d-r}{\gamma r}\right)\right) \frac{1}{\gamma r|v|} & \text { if } v>-\frac{e^{-\gamma\left(b_{e}+\frac{\rho+d-r}{\gamma r}\right)}}{r}\end{cases} \\
& h_{u}(v)= \begin{cases}g_{1}\left(\frac{1}{r}\left(-\frac{1}{\gamma} \log (-r v)-b_{u}-\frac{\rho+d-r}{\gamma r}\right)\right) \frac{1}{\gamma r|v|} & \text { if } v<-\frac{e^{-\gamma\left(b_{u}+\frac{\rho+d-r}{\gamma r}\right)}}{r} \\
g_{2}\left(\frac{1}{r}\left(-\frac{1}{\gamma} \log (-r v)-b_{u}-\frac{\rho+d-r}{\gamma r}\right)\right) \frac{1}{\gamma r|v|} & \text { if } v>-\frac{e^{-\gamma\left(b_{u}+\frac{\rho+d-r}{\gamma r}\right)}}{r}\end{cases}
\end{aligned}
$$

\subsection{Derivation of First Order Conditions for the Vacancy Creation Problem}

This section sets out the first order conditions associated with optimality for the firm's problem. First, we can rewrite our constraint as $q_{j}\left(\theta_{j}\right) \cdot \frac{x_{j} f\left(k_{j}\right)-w_{j}}{\left(r_{f}+\delta_{j}+d\right)\left(q_{j}\left(\theta_{j}\right)+r_{f}\right)}=k_{j}$ where we have substituted the steady state value of a firm with a filled position into the constraint and rearranged. The corresponding Lagrangian for this problem is

$$
\mathcal{L}=V_{u}(a)+\lambda\left(\frac{q(\theta)(x f(k)-w)}{\left(r_{f}+\delta+d\right)\left(r_{f}+q(\theta)\right)}-k\right)
$$

and the first order conditions with respect to $w$ and $\theta$ are:

$$
\begin{aligned}
\mathcal{L}_{w} & =\frac{\partial V_{u}(a)}{\partial w}-\lambda\left(\frac{q(\theta)}{\left(r_{f}+\delta+d\right)\left(r_{f}+q(\theta)\right)}\right)=0 \\
\mathcal{L}_{\theta} & =\frac{\partial V_{u}(a)}{\partial \theta}+\lambda\left(q^{\prime}(\theta) \frac{x f(k)-w}{\left(r_{f}+\delta+d\right)\left(r_{f}+q(\theta)\right)}-\frac{q^{\prime}(\theta) q(\theta)(x f(k)-w)}{\left(r_{f}+\delta+d\right)\left(r_{f}+q(\theta)\right)^{2}}\right)=0
\end{aligned}
$$

and the first order condition with respect to capital leads to equation (5). To derive equation (6) recall

$$
V_{u}(a)=-\frac{e^{-\gamma\left(r a+b_{u}+\frac{\rho+d-r}{\gamma r}\right)}}{r}
$$

so

$$
\begin{aligned}
& \frac{\partial V_{u}(a)}{\partial \theta}=\frac{-e^{-\gamma c_{u}}}{r}(-\gamma) \frac{\partial b_{u}}{\partial \theta} \\
& \frac{\partial V_{u}(a)}{\partial w}=\frac{-e^{-\gamma c_{u}}}{r}(-\gamma) \frac{\partial b_{u}}{\partial w}
\end{aligned}
$$


However, $b_{u}$ is determined in conjunction with $b_{e}$ as part of a system of equations. We may use the implicit function theorem to evaluate $\frac{\partial b_{u}}{\partial \theta}$ and $\frac{\partial b_{u}}{\partial w}$. This leads to the following observation:

$$
\frac{\frac{\partial V_{u}(a)}{\partial \theta}}{\frac{\partial V_{u}(a)}{\partial w}}=\frac{\frac{\partial b_{u}(a)}{\partial \theta}}{\frac{\partial b_{u}(a)}{\partial w}}=\frac{\left(e ^ { \gamma ( b _ { e , j } - b _ { u , j } ) - 1 ) } \left(\delta+r+\gamma r\left((1-\tau) w_{j}-b_{e, j}\right)\right.\right.}{\gamma r(1-\tau)} \cdot \frac{\lambda_{j}^{\prime}\left(\theta_{j}\right)}{\lambda_{j}}
$$

Using this result, together with the first order conditions associated with $w$ and $\theta$ (presented above) leads to equation (6). Finally, equation (7) is simply the constraint.

\subsection{Equilibrium in the Goods Market}

Our equilibrium in the goods market requires that demand,

$$
\begin{aligned}
D & =\sum_{j} \pi_{j}\left(\int_{-\infty}^{\infty} c_{u, j}(a) g_{j}(a) d a+\int_{-\infty}^{\infty} c_{e, j}(a) f_{j}(a) d a\right)+k_{j} \cdot \lambda_{j}\left(\theta_{j}\right) \cdot u_{j} \\
& =\sum_{j} u_{j} \cdot b_{u, j}+\left(\pi_{j}-u_{j}\right) \cdot b_{e, j}+\pi_{j} \cdot \frac{\rho+d-r}{\gamma r} \\
& +\frac{r}{d}\left(\left(\pi_{j}-u_{j}\right)\left(y_{e, j}-b_{e, j}\right)+u_{j}\left(y_{u, j}-b_{u, j}\right)+\pi_{j} \frac{r-\rho-d}{\gamma r}\right)+k_{j} \cdot \lambda_{j}\left(\theta_{j}\right) \cdot u_{j} .
\end{aligned}
$$

equals supply,

$$
Y=\sum_{j} u_{j} \cdot z+\left(\pi_{j}-u_{j}\right) \cdot x_{j} f\left(k_{j}\right)
$$

Note that using our definition of aggregate assets we can rewrite this condition as

$$
\sum_{j}\left(u_{j} \cdot b_{u, j}+\left(\pi_{j}-u_{j}\right) \cdot b_{e, j}+\pi_{j} \cdot \frac{\rho+d-r}{\gamma r}+k_{j} \cdot \lambda_{j}\left(\theta_{j}\right) \cdot u_{j}\right)+\left(r_{f}+d\right) A=\sum_{j} u_{j} \cdot z+\left(\pi_{j}-u_{j}\right) \cdot x_{j} f\left(k_{j}\right)
$$

Rearranging, we find,

$$
\sum_{j} k_{j} \cdot \lambda_{j}\left(\theta_{j}\right) \cdot u_{j}+\left(r_{f}+d\right) A=\sum_{j} u_{j} \cdot\left(z-b_{u, j}\right)+\left(\pi_{j}-u_{j}\right) \cdot\left(x_{j} f\left(k_{j}\right)-b_{e, j}\right)-\pi_{j} \cdot \frac{\rho+d-r}{\gamma r}
$$

The right hand side of this expression can be rewritten as

$$
\begin{aligned}
& \sum_{j} u_{j} \cdot\left(z-y_{u, j}+y_{u, j}-b_{u, j}\right)+\left(\pi_{j}-u_{j}\right) \cdot\left(x_{j} f\left(k_{j}\right)-y_{e, j}+y_{e, j}-b_{e, j}\right)-\pi_{j} \cdot \frac{\rho+d-r}{\gamma r} \\
& =d A+\sum_{j} u_{j} \cdot\left(z-y_{u, j}\right)+\left(\pi_{j}-u_{j}\right) \cdot\left(x_{j} f\left(k_{j}\right)-y_{e, j}\right)
\end{aligned}
$$

Using the above we can rewrite 13 as

$$
\sum_{j} k_{j} \cdot \lambda_{j}\left(\theta_{j}\right) \cdot u_{j}+\left(r_{f}+d\right) A=d A+\sum_{j} u_{j} \cdot\left(z-y_{u, j}\right)+\left(\pi_{j}-u_{j}\right) \cdot\left(x_{j} f\left(k_{j}\right)-y_{e, j}\right)
$$

and using the budget balance condition this simplifies to equation (11). 


\section{References}

Acemoglu, Daron \& Robert Shimer. 1999. "Efficient Unemployment Insurance." The Journal of Political Economy 107(5):893-928.

Aguiar, Mark \& Erik Hurst. 2005. "Consumption versus Expenditure." Journal of Political Economy 113(5):919-948.

Aiyagari, S. Rao. 1994. "Uninsured Idiosyncratic Risk and Aggregate Saving." The Quarterly Journal of Economics 109(3):659-684.

Blanchard, Olivier J. 1985. "Debt, Deficits, and Finite Horizons." Journal of Political Economy 93(2):223247.

Borowczyk-Martins, Daniel, Gregory Jolivet \& Fabien Postel-Vinay. 2013. "Accounting for endogeneity in matching function estimation." Review of Economic Dynamics 16:440-451.

Browning, Martin, Thomas F. Crossley \& Eric Smith. 2007. "Asset Accumulation and Short-Term Employment." Review of Economic Dynamics 10:400-423.

Cairo, Isabel \& Tomaz Cajner. 2014. "Human Capital and Unemployment Dynamics: Why More Educated Workers Enjoy Greater Employment Stability." Finance and Economics Discussion Series 2014-09, Divisions of Research 8 Statistics and Monetary Affairs .

Costain, James S. 1995. "General Equilibrium Unemployment Insurance: the Exponential Utility Case." Mimeo, UPF.

Diamond, Peter A. \& Joel Yellin. 1985. "The Distribution of Inventory Holdings in a Pure Exchange Barter Search Economy." Econometrica 53(2):409-432.

Diamond, Peter A. \& Joel Yellin. 1990. "Inventory and Money Holdings in a Search Economy." Econometrica 58(4):929-950.

Farber, Henry S. 2008. "Employment Insecurity: The Decline in Worker-Firm Attachment in the United States." Working Paper, Princeton University, Industrial Relations Section .

Flemming, J. S. 1978. "Aspects of Optimal Unemployment Insurance." Journal of Public Economics 10:403425.

Geromichalos, Athanasios. 2015. "Unemployment insurance and optimal taxation in a search model of the labour market." Review of Economic Dynamics 18(2):365-380.

Gomes, Joao, Jeremy Greenwood \& Sergio Rebelo. 2001. "Equilibrium Unemployment." Journal of Monetary Economics 48(1):109-152. 
Hansen, Gary D. \& Ayse Imrohoroglu. 1992. "The Role of Unemployment Insurance in an Economy with Liquidity Constraints and Moral Hazard." The Journal of Political Economy 100(1):118-142.

Hopenhayn, Hugo A. \& Juan Pablo Nicolini. 1997. "Optimal Unemployment Insurance." The Journal of Political Economy 105(2):412-438.

Krueger, Alan B., Judd Cramer \& David Cho. 2014. "Are the Long-Term Unemployed on the Margins of the Labor Market?" Brookings Papers on Economic Activity pp. 229-280.

Krusell, Per, Toshihiko Mukoyama \& Ayşegül Şahin. 2010. "Labour-Market Matching with Precautionary Savings and Aggregate Fluctuations." Review of Economic Studies 77(4):1477-1507.

Krusell, Per, Toshihiko Mukoyama, Richard Rogerson \& Ayşegül Şahin. 2008. "Aggregate Implications of Indivisible Labor, Incomplete Markets and Labour Market Frictions." Journal of Monetary Economics 55:961-979.

Lawrance, Emily C. 1991. "Poverty and the Rate of Time Preference: Evidence from Panel Data." Journal of Political Economy 99(1):54-77.

Lifschitz, Avihai, Ofer Setty \& Yaniv Yedid-Levi. 2016. "Who Cares About Unemployment Insurance." Mimeo.

Lise, Jeremy. 2007. "On-the-Job Search and Precautionary Savings: Theory and Empirics of Earnings and Wealth Inequality." Mimeo, UCL.

Marceau, Nicolas \& Robin Boadway. 1994. "Minimum Wage Legislation and Unemployment Insurance as Instruments for Redistribution." Scandinavian Journal of Economics 96(1):67-81.

Moen, Espen R. 1997. "Competitive Search Equilibrium.” The Journal of Political Economy 105(2):385-411.

Mukoyama, Toshihiko. 2013. "Understanding the welfare effects of unemployment insurance policy in general equilibrium." Journal of Macroeconomics 38:347-368.

Pollak, Andreas. 2007. "Optimal Unemployment Insurance with Heterogeneous Agents." European Economic Review 51(8):2029-2053.

Robert E. Lucas, Jr. \& Edward C. Prescott. 1974. "Equilibrium Search and Unemployment." Journal of Economic Theory 7(2):188-209.

Shimer, Robert. 2005. "The Cyclical Behavior of Equilibrium Unemployment and Vacancies." The American Economic Review 95(1):25-49.

Shimer, Robert \& Ivan Werning. 2007. "Reservation Wages and Unemployment Insurance." The Quarterly Journal of Economics 122(3):1145-1185. 
Shimer, Robert \& Ivan Werning. 2008. "Liquidity and Insurance for the Unemployed." American Economic Review 98(5):1922-1942.

Wang, Neng. 2007. "An Equilibrium Model of Wealth Distribution." Journal of Monetary Economics $54(7): 1882-1904$.

Yaari, Menahem E. 1965. "Uncertain Lifetime, Life Insurance, and the Theory of the Consumer." The Review of Economic Studies 32(2):137-150. 